\title{
La ARquitectura foliar de las especies de Lauraceae Nativas de Misiones, Argentina
}

\author{
PABLO A. POSZKUS BORRERO ${ }^{1}$, ALICIA V. BOHREN¹, HÉCTOR A. KELLER ${ }^{1,2}$, LUIS A. \\ GRANCE ${ }^{1}$ y CLAUDIO J. DUMMEL ${ }^{1}$
}

\begin{abstract}
Resumen: La arquitectura foliar de 12 especies leñosas de la familia Lauraceae que crecen en la Provincia de Misiones (Argentina) fueron estudiadas con el objetivo de contribuir al conocimiento de las mismas. Las especies se caracterizan por presentar hojas simples, pecioladas, de ápice generalmente acuminado y con o sin domacios. Los patrones de venación de primero, segundo, tercero, cuarto y quinto orden fueron descriptos e ilustrados para las especies estudiadas; éstas presentan una venación secundaria de varios tipos: broquidódroma (Nectandra megapotamica, Cryptocarya aschersoniana, Ocotea diospyrifolia, Endlicheria paniculata, Ocotea puberula y Ocotea sp.), acródroma suprabasal imperfecta-broquidódroma (Cinnamomum amoenum, Ocotea pulchella), craspedódroma (Ocotea acutifolia) y eucantódromo-broquidódroma (Nectandra lanceolata, Nectandra angustifolia, Ocotea lancifolia). La densidad de areolas fue observada como un carácter diagnóstico importante; no siendo el caso del número de lados que éstas poseen. Todas las especies presentaron estomas paracíticos. Los caracteres analizados, junto con los morfológicos y epidérmicos, permitieron la diferenciación de las 12 especies estudiadas, evidenciando la importancia de la arquitectura foliar en el reconocimiento en estado vegetativo. Por primera vez para la flora Argentina, Endlicheria paniculata es citada en esta contribución.
\end{abstract}

Palabras clave: Venación, areolas, Selva Misionera, estomas, domacios.

\begin{abstract}
Summary: Leaf architecture of native Lauraceae species from Misiones, Argentina. The leaf architecture of 12 woody species of Lauraceae family that grows in Province of Misiones (Argentina) was studied with the aim of contributing to knowledge of them. The species are characterized by simple leaves, petioles, apex usually acuminate and with or without domatia. Venation patterns first, second, third, fourth and fifth order were described and illustrated for the species studied; these one presents the secondary venation from several types: brochidodromous (Nectandra megapotamica, Cryptocarya aschersoniana, Ocotea diospyrifolia, Endlicheria paniculata, Ocotea puberula and Ocotea sp.) acrodromous suprabasal imperfect -brochidrodromous (Cinnamomum amoenum, Ocotea pulchella), craspedodromous (Ocotea acutifolia) and eucamtodromous-brochidodromous (Nectandra lanceolata, Nectandra angustifolia, Ocotea lancifolia). Areoles density was observed as an important diagnostic character; not being the case on the number of sides they have. All species showed paracytic stomata. The characters analyzed, together with morphologic and epidermal, allowed differentiation of the 12 tested species, demonstrating the importance of leaf architecture in vegetative state recognition. First time for the Argentinian flora, Endlicheria paniculata is mentioned in this contribution.
\end{abstract}

Key words: Venation, areoles, Atlantic Forest; stomata, domatia.

\section{INTRODUCCIÓN}

La familia Lauraceae tiene una distribución fitogeográfica amplia, especialmente en la región

\footnotetext{
1 Universidad Nacional de Misiones, Facultad de Ciencias Forestales, Bertoni 124, Eldorado, Misiones, CP: 3380, pabloposzkus@yahoo.com.ar, aliciabohren@hotmail. com, Igrance@yahoo.com.ar, cdummel@yahoo.com.ar

2 Instituto de Botánica del Nordeste. Sargento Cabral 2131, Corrientes, e-mail hakeller2000@yahoo.com.ar
}

Pantropical, concentrándose la mayor diversidad de especies en regiones Indomalayas y del Centro y Sur de América (Rohwer, 1993). Comprende unas 2.500 a 3000 especies agrupadas en 50 géneros (Chanderbali et al., 2001). Argentina cuenta con 5 géneros y 16 especies arbóreas; de las cuales en la Provincia de Misiones se registran 4 géneros y 10 especies (Zuloaga et al., 2009). En las comunidades de la Selva Misionera, las especies arbóreas de la familia Lauraceae, se destacan por su diversidad y por ser pioneras al formarse un claro en el bosque (Cabrera, 1994). 
Algunas especies de Lauráceas presentan maderas de excelente calidad, otras son utilizadas en artes culinarias, en medicina popular, en fabricación de papel y en industrias químicas y farmacéuticas (Klein et al., 1979; Inoue et al., 1984; Marques, 2001; Brotto et al., 2009). Sumándose a la importancia económica, en las comunidades neotropicales donde prosperan Lauráceas -incluidas las argentinas, reúnen importancia ecológica tanto en aspectos funcionales como estructurales. Por otra parte, las especies de esta familia están presentes en los más variados hábitats, desde el nivel del mar hasta los páramos andinos, siendo recurrentemente una de las familias de especies arbóreas más frecuentes en los inventarios botánicos (Van der Werff \& Richter, 1996; Baitello, 2001; Moraes, 2005). A pesar de su importancia, esta familia se encuentra en permanente revisión en términos de su clasificación, número y distribución geográfica (Van der Werff \& Richter, 1996) caracterizándose por su dificultad de identificación y delimitación de muchas de sus especies (Moraes, 2005). Dentro de los estudios disponibles sobre la arquitectura foliar de esta familia, el trabajo de Gomes Bezerra et al. (2011) caracteriza los patrones de venación de las especies presentes en el Distrito Federal (Brasil), identifica características útiles para la diferenciación taxonómica, junto con otros caracteres morfológicos, los cuales posibilitaron distinguir 18 especies de Lauraceae; este aporte dió trascendencia a la arquitectura foliar como herramienta en la identificación vegetativa de las especies. En el mismo sentido, pero para otras familias botánicas, Guantay (2004a, b y 2008), analizó la morfoanatomía y arquitectura foliar de tres especies de Myrtaceae de las que describió los tipos de venación presentes. Por otro lado Ruiz et al. (2009) estudiaron la morfoanatomía y arquitectura foliar de Schinus areira L., describieron y caracterizaron el tipo de venación presente. Así mismo, Malla et al. (1998) caracterizaron la arquitectura foliar de tres géneros monotípicos de Fabaceae, con el fin de generar datos para la caracterización taxonómica. Gonzáles (2011a, b, c) estudió a 19 especies de Myrtaceae, con el objetivo de caracterizar patrones de la arquitectura foliar para diferenciarlas. Otros autores trabajaron sobre patrones de venación y arquitectura foliar, y entre ellos se destacan los de Romero \& Dibbern (1982), Mantese \& Medan (1992), Luo \& Zhou (2002),
Martínez Cabrera et al. (2003), Cardoso \& Sajo (2004 y 2006), Martínez Millán \& Cevallos Ferriz (2005) y Sack et al. (2012).

En Argentina, los antecedentes sobre los estudio de arquitectura foliar son escasos; los existentes abordan aspectos anatómicos de las hojas. Por lo expuesto, este trabajo pretende contribuir y enriquecer conocimientos sobre arquitectura foliar de esta familia muy importante en la Provincia de Misiones.

\section{Materiales y Métodos}

El área de estudio comprende la Provincia de Misiones, Argentina. El clima es del tipo CFA, según la clasificación de Köppen (1948), macrotérmico, constantemente húmedo $\mathrm{y}$ subtropical. Las precipitaciones anuales presentan un rango de $1.500-2.000 \mathrm{~mm}$. La temperatura media anual es de $21{ }^{\circ} \mathrm{C}$. El terreno es ondulado, con pendientes suaves a muy pronunciadas y variaciones altitudinales comprendidas entre los 267 y 800 m.s.n.m. (Palavecino \& Maiocco, 1995).

Se presenta a continuación el listado de las especies registradas en la provincia de Misiones (Tabla 1), obtenidas del Catálogo de Plantas Vasculares de la Argentina (Zuloaga et al., 2009); incluyéndose además dos especies aún no citadas para Argentina, una de las cuales ha sido identificada sólo a nivel de género.

El material de estudio fue recolectado en campo, posteriormente herborizado y debidamente rotulado (Tabla 1). Se recolectaron rámulos de la parte media de la copa para evitar diferencias por exposiciones diferentes a luz y sombra. Asimismo, se seleccionaron hojas que se encuentren totalmente desarrolladas (parte media del rámulo) y con excelente estado fitosanitario. Se analizaron de tres a cinco hojas por individuo de cada especie, de acuerdo con la recomendación sugerida por Gomes Bezerra et al. (2011). Adicionalmente, se recolectó material de herbario de cada especie estudiada, el mismo se halla depositado en el herbario CTES del Instituto de Botánica del Nordeste, Corrientes, Argentina.

El material colectado a campo se sometió a la técnica de diafanización propuesta por Dizeo de Stritmatter (1973). Para el estudio epidérmico de la hoja se adaptó la técnica de "peeling" de Ghouse \& Yunus (1972) descripto en Ruzin (1999) 
Tabla 1. Listado de especies de Lauraceae de la Selva Misionera (Herbario CTES)

\begin{tabular}{|ll|}
\hline \multicolumn{1}{|c|}{ Especie } & \multicolumn{1}{c|}{ Material de Referencia } \\
\hline Cinnamomum amoenum (Nees) Kosterm. & Tressens et al 4658 \\
\hline Cryptocarya aschersoniana Mez. & Keller \& Franco 8293 \\
Endlicheria paniculata (Sprengel) Macbride. & Keller et al 10420 \\
Nectandra lanceolata Nees. & Tressens et al 4650 \\
Nectandra megapotamica (Spreng.) Mez. & Tressens et al 5409 \\
Nectandra angustifolia (Shard.) Nees \& Mart. ex Nees. & Keller \& Keller 10635 \\
Ocotea acutifolia (Nees) Mez. & Keller \& Krauczuk 11297 \\
Ocotea diospyrifolia (Meisn.) Mez. & Tressens et al 6468 \\
Ocotea lancifolia (Schott) Mez. & Keller \& Franco 5656 \\
Ocotea puberula (Rich) Nees & Tressens et al 5658 \\
Ocotea pulchella (Nees) Mez. & Tressens et al 5120 \\
Ocotea sp. & Keller et al 10365 \\
\hline
\end{tabular}

y las descripciones se realizaron conforme a la clasificación desarrollada por Hickey (1974 y 1979) y Ash et al. (1999).

Para las descripciones de los estomas se utilizó la clasificación de Prabhakar (2004). La caracterización de los estomas, determinación del índice estomático (IE) y de densidad estomática (DE) se realizaron de acuerdo a la fórmula propuesta por Wilkinson (1979):

Donde $\mathrm{S}$ es el número de estomas que hay por unidad de área y $\mathrm{E}$ es el número de células epidérmicas que hay por unidad de área. La DE se obtuvo contando el número de estomas que se encuentra en un área de $1 \mathrm{~mm}^{2}$.

Los materiales fueron observados con Microscopio Estereoscópico Zeiss. Se utilizó una Cámara digital Moticam con software para mediciones y un Scanner HP para las fotografías de rámulos y hojas diafanizadas.

Con la información recopilada mediante la metodología expuesta y consultas bibliográficas, se describió las características exomorfológicas, de venación y epidérmicas de las hojas; con las mismas se elaboró una clave dicotómica con el fin de facilitar el reconocimiento de las especies.

\section{Resultados}

A continuación se presentan las descripciones de las características observadas a nivel foliar de las 12 especies nativas de la familia Lauraceae que crecen en la Selva Misionera concurrente en la Provincia de Misiones. Cabe mencionar que durante las campañas para la obtención de material se colectaron dos especies no registradas para la flora de la Argentina, una de ellas sólo pudo identificarse a nivel de género, la otra es Endichleria paniculata (Sprengel) Macbride, citándose en el presente trabajo material de referencia que permite documentarla por primera vez para nuestro país, se cita el material de referencia en el tratamiento de esa especie.

Las descripciones de las especies se dividieron en tres partes: Exomorfología, Venación y Epidermis.

Cinnamomum amoenum (Nees) Kosterm (Fig. 1):

Exomorfología: Hojas lanceoladas, elípticas a obovadas; de 5 a $12 \mathrm{~cm}$ de longitud y de 2 a $3,5 \mathrm{~cm}$ de ancho; ápice cortamente acuminado; base aguda a levemente atenuada; y levemente revoluto en la base de la lámina; cara adaxial glabra; cara abaxial velloso a glabrescente. Presenta domacios del tipo escrobícula; relación L:W (largo: ancho) 2,5:1 a 3,4:1. Pecíolo de 0,5-1 $\mathrm{cm}$ de largo, canaliculado, glabrescente, sección transversal acanalado.

Venación: vena primaria pinnada, inmersa en la cara adaxial y prominente en la cara abaxial. Venación secundaria acródromo-broquidódroma; la venación acródroma es supra basal imperfecta; 4-5 pares nervaduras secundarias, con 


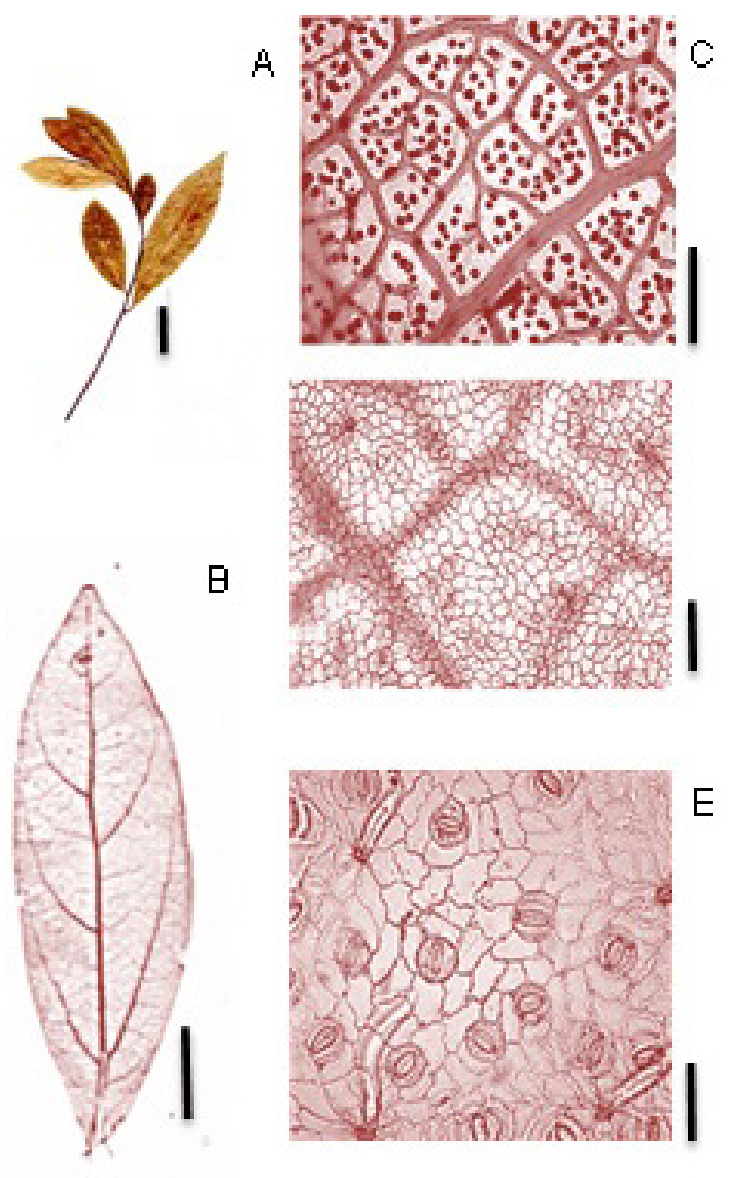

Fig. 1. Cinnamomum amoenum (Nees) Kosterm. A: Rámulo. B: Hoja diafanizada. C: Detalle venas terciarias, areolas y vénulas. D: Epidermis en la cara adaxial. E: Cara abaxial- detalle de los estomas. Escalas: A: 2 cm., B: 1 cm., C: $500 \mu \mathrm{m}$, D: $50 \mu \mathrm{m}, \mathrm{E}: 25 \mu \mathrm{m}$. .

distanciamiento irregular, creciente hacia la base; nervaduras inter-secundarias exmediales frecuentes; nervaduras terciarias alterno-opuestas percurrentes; venas del $4^{\circ}$ orden de venación alternas percurrentes; $5^{\circ}$ orden de venación se anastomosan con otras venas formando un reticulado de polígonos regulares; areolas de 4-5 lados, 2- 4 areolas $/ \mathrm{mm}^{2}$; vénulas simples a ramificadas una vez; vena marginal tipo fimbrial.

Epidermis: Estomas presentes solamente en la cara abaxial de la lámina; estomas tipo paracitico. Número de estomas por milímetro cuadrado de 400-1600 (media: 1000) estomas $/ \mathrm{mm} 2$, el número de células epidérmicas $/ \mathrm{mm}^{2}$ es de 4100 6000 (media: 5050) y el índice estomático es 0,16 (16\%). Estomas visibles con aumento de 10X. Las células epidérmicas fundamentales en la cara adaxial son poligonales de paredes rectas, mientras que en la cara abaxial son poligonales de paredes onduladas (lobuladas).

Material de referencia: Tressens et al. 4658 (CTES).

\section{Cryptocarya aschersoniana Mez (Fig. 2):}

Exomorfología: Hojas estrechamente elíptica, alternas, con lámina de 5 a $10 \mathrm{~cm}$ de largo y de 2,5 a 3,5 cm de ancho; de borde entero algo ondulado, ápice cortamente acuminado, base cuneada y simétrica; cara adaxial glabra, cara
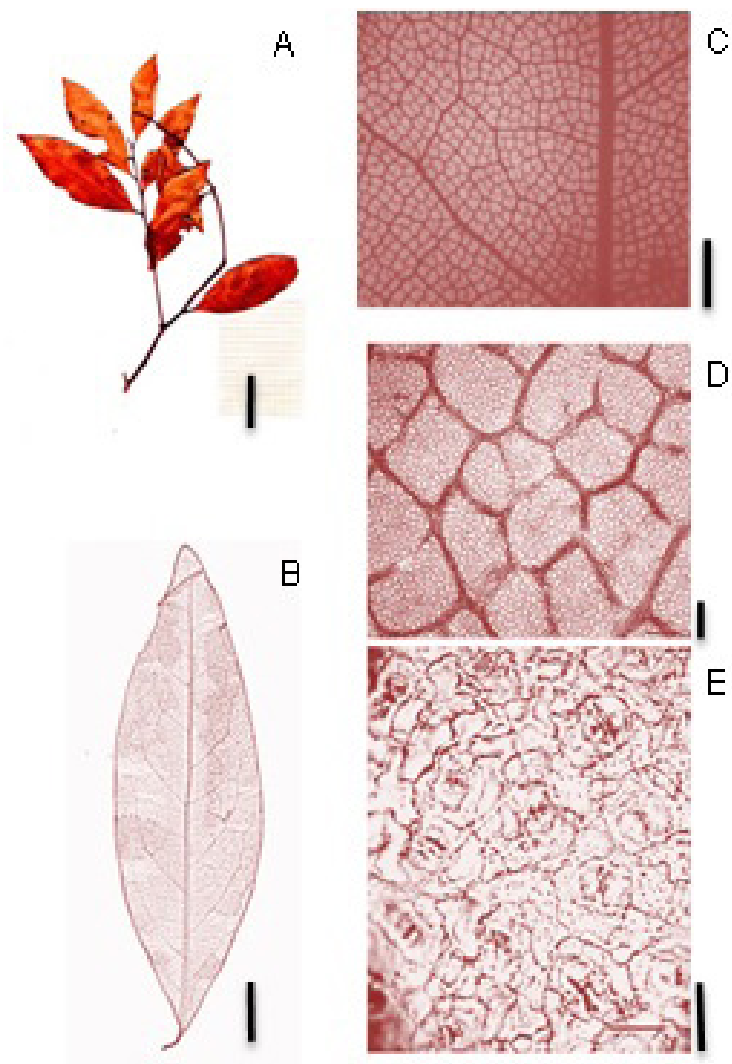

Fig. 2. Cryptocarya aschersoniana Mez. A: Rámulo. B: Hoja diafanizada. C: Detalle venas terciarias, areolas y vénulas. D: Epidermis en la cara adaxial. E: Cara abaxial- detalle de los estomas. Escalas: A: $3 \mathrm{~cm}, \mathrm{~B}: 2 \mathrm{~cm}, \mathrm{C}: 2 \mathrm{~mm}$, D: $100 \mu \mathrm{m}, \mathrm{E}: 25 \mu \mathrm{m}$. 
abaxial glabrescente en la lámina, vena primaria glabrescente inmersa en el haz y prominente en el envés de la lámina; relación L:W (largo:ancho) 4:1 a 6:1; no presentan domacios. Pecíolo de 0,5- $1 \mathrm{~cm}$ de largo, color negruzco, canaliculadobilobulado, glabrescente.

Venación: Categoría de venación primaria es de tipo pinnada; venación secundaria broquidódroma, 7- 11 pares de venas secundarias, espaciamiento entre venas secundarias es regular, venas intersecundarias poco frecuentes; $3^{\circ}$ categoría de venación alternos a subopuestos percurrentes, las venas terciaras se anastomosan para formar un reticulado de polígonos regulares, el curso de las venas $3^{\circ}$ es sinuosa, con ramificación exmedial, $4^{\circ}$ categoría de venación alternas percurrentes, se anastomosan con otras venas formando un reticulado de polígonos regulares; $5^{\circ}$ orden de venación se anastomosan con otras venas formando un reticulado de polígonos regulares; areolas bien definidas, de 45 lados, 2-3 areolas $/ \mathrm{mm}^{2}$; vénulas simples a $1 \mathrm{vez}$ ramificada; ultimo orden de venación $5^{\circ}$; ultima vena marginal de tipo fimbrial.

Epidermis: Estomas presentes únicamente en la cara abaxial de la lámina; estomas tipo paracítico. Número de estomas por milímetro cuadrado es 400-800 (media: 600) estomas $/ \mathrm{mm}^{2}$, el número de células epidérmicas $/ \mathrm{mm}^{2}$ es de 3000 4000 (media: 3500) y el índice estomático es de 0,15 (15\%). Estomas poco visibles (perceptibles) en aumentos de 10X. Las células epidérmicas fundamentales en la cara adaxial son poligonales con paredes fuertemente onduladas (lobuladas), mientras que en la cara abaxial son poligonales de contorno poco definido con paredes suavemente onduladas (suavemente lobuladas).

Material de referencia: Keller \& Franco 8293 (CTES).

\section{Endlicheria paniculata (Sprengel) Macbride (Fig. 3):}

Exomorfología: Hojas elípticas, alternas, de 7 a 17,5 cm de largo y de 3 a $7 \mathrm{~cm}$ de ancho, relación L:W (largo: ancho) de 2:1 a 5:1; lámina simétrica, borde entero, ápice acuminado, base simétrica a levemente asimétrica, base cuneada; cara adaxial algo pubescente sobre la lámina, y fuertemente pubescente sobre la vena primaria y venas secundarias también fuertemente pubescentes,
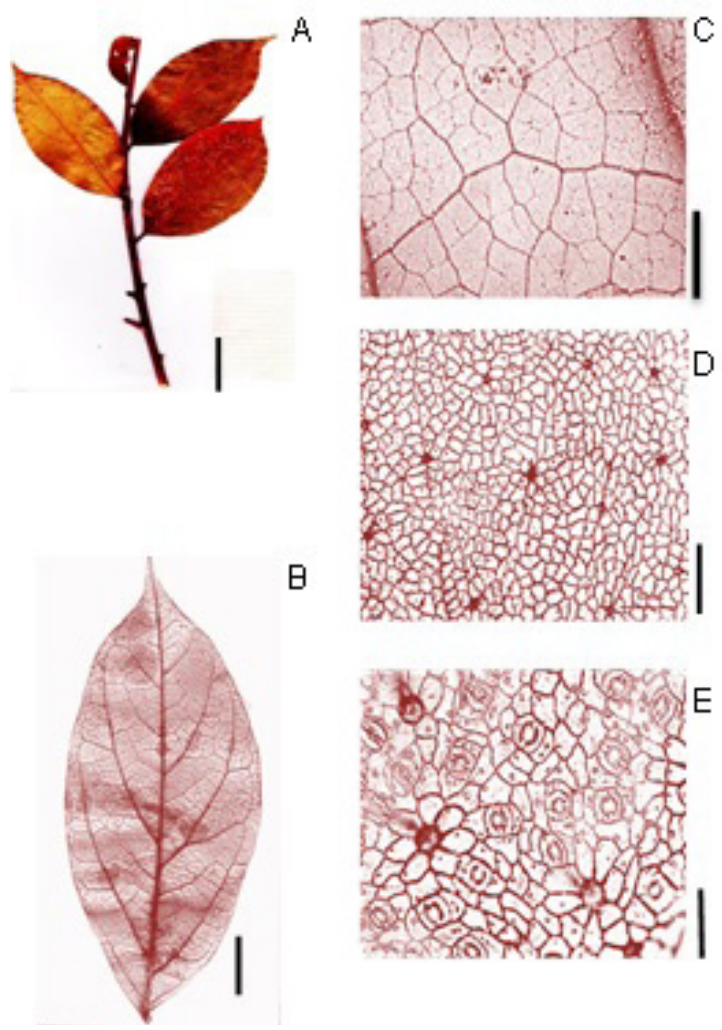

Fig. 3. Endlicheria paniculata (Sprengel) Macbride. A: Rámulo. B: Hoja diafanizada. C: Detalle venas terciarias, areola y vénulas. D: Epidermis en la cara adaxial. E: Cara abaxial- detalle de los estomas. Escala: A: $3 \mathrm{~cm}, \mathrm{~B}: 3 \mathrm{~cm}, \mathrm{C}: 1 \mathrm{~mm}, \mathrm{D}: 60 \mu \mathrm{m}, \mathrm{E}: 25$ $\mu \mathrm{m}$.

color ferruginoso, nervadura $1^{\circ}$ levemente pubescente sobre el ápice; cara abaxial levemente pubescente sobre la lámina y fuertemente pubescente sobre las nervadura primaria, y más laxa en las secundarias, la pubescencia de la cara abaxial es de un color ferrugíneo claro que la del haz; no presenta domacios. Pecíolo de 1- 1,5 $\mathrm{cm}$ de largo, pubescente de color ferruginoso, sección transversal asimétrica bilobulada en la parte abaxial del peciolo.

Venación: Orden de venación $1^{\circ}$ de tipo pinnada; $2^{\circ}$ categoría de venación del tipo broquidódroma, 5-8 pares de venas secundarias; venas secundarias con espaciamiento irregular, venas intersecundarias poco presentes; $3^{\circ}$ categoría de venación alterno percurrentes, el curso de la vena $3^{\circ}$ es sinuoso, ramificación 
exmedial, $4^{\circ}$ categoría de venación se anastomosan formando un reticulado regular, alterno percurrente; $5^{\circ}$ orden de venación formando un reticulado poligonal regular; areolas de 4- 5 a más lados; 2-3 areolas $/ \mathrm{mm}^{2}$; vénulas dendríticas; ultimo orden de venación $5^{\circ}$; ultima vena marginal tipo fimbrial.

Epidermis: Estomas presentes únicamente en la cara abaxial de la lámina. Estomas del tipo paracítico. Número de estomas por milímetro cuadrado es de 700-1000 (media: 850) estomas/ $\mathrm{mm}^{2}$, el número de células epidérmicas por $\mathrm{mm}^{2}$ es de 2000-6000 (media: 4000) y el índice estomático es de 0,17 (17\%). Estomas bien visibles en aumentos de $10 \mathrm{X}$ ver en $4 \mathrm{x}$. Las células epidérmicas fundamentales en la cara adaxial y abaxial son rectangulares a poligonales con paredes rectas.

Material examinado: ARGENTINA, Misiones, Iguazú, Acceso hacia Puerto Iguazú, alrededores de complejo Hotel Orquídeas, fr, 10-X-2011, Keller \& Küpers 10364 (CTES). Ídem. parte posterior a Hotel Orquídeas, $25^{\circ} 37^{\prime}$ 31,6 " S 54 $33^{\circ} 10,2$ ' W, 15-X-2011, Keller et al., 10378 (CTES). Ídem. $25^{\circ} 37^{\prime} 30,9$ ' S 54 ${ }^{\circ}$ 33' 09,2" W, 27-X-2011, Keller et al., 10420 (CTES). Ídem. $25^{\circ} 37^{\prime} 33^{\prime \prime} \mathrm{S} \mathrm{54}{ }^{\circ} 33^{\prime} 08,7^{\prime}$ 'W, 27-X-2011, Keller \& et al., 10422 (CTES) Ídem. Puerto Iguazú, Las 600 has, $25^{\circ} 36^{\prime} 11,6^{\prime \prime} \mathrm{S} 54^{\circ}$ 33' 36,9''W, 27-X-2011, Keller \& et al., 10413 (CTES). Ídem. Puerto Iguazú, Las 600 has, $25^{\circ}$ 36' 11,6" S 54 33' 36,9''W, 27-X-2011, Keller \& et al., 10413 (CTES).

Nectandra angustifolia (Shard.) Nees \& Mart. ex Nees (Fig. 4):

Exomorfología: Hojas linear lanceoladas, alternas, de 6- $15 \mathrm{~cm}$ de largo y de 0,5- $2 \mathrm{~cm}$ de ancho, ápice suavemente acuminado; base cuneada, simétrica a levemente asimétrica; cara adaxial glabra; cara abaxial levemente pubescente; no presenta domacios; relación L:W (largo:ancho) 7,5:1 a 12:1. Pecíolo de 0,3 a 1 $\mathrm{cm}$ de largo, glabrescente, sección transversal trilobulado.

Venación: La categoría de venación primaria es pinnada; la venación secundaria es de tipo broquidódromo-eucantódroma, 10-15 pares de venas $2^{\circ}$; el espaciamiento de las venas secundarias es irregular; venas intersecundarias
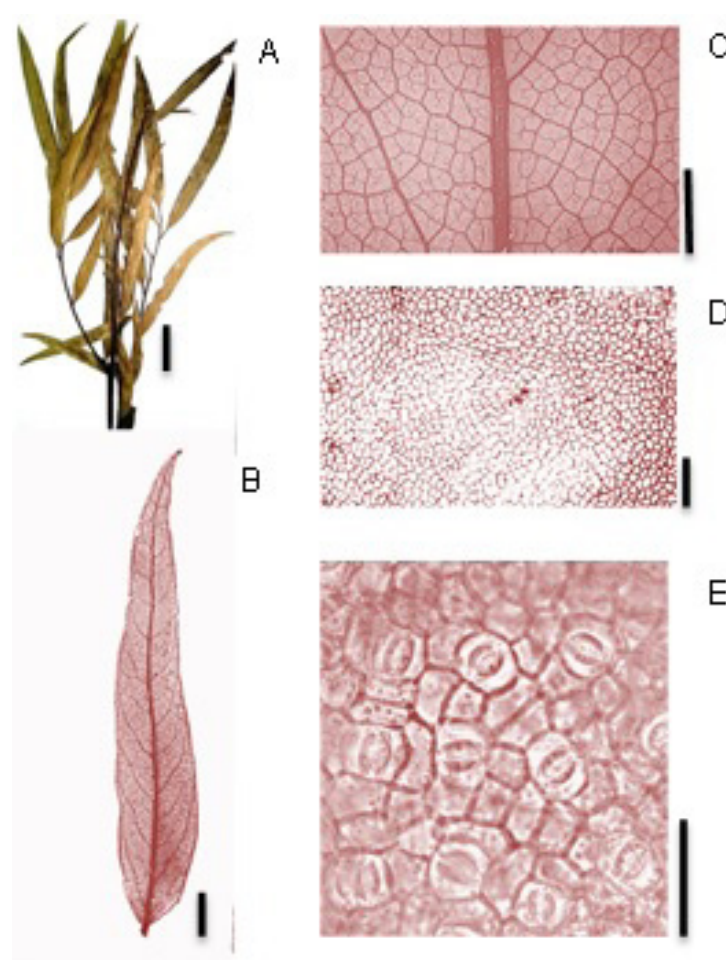

E

Fig. 4. Nectandra angustifolia (Shard.) Nees \& Mart. ex Nees. A: Rámulo. B: Hoja diafanizada. C: Detalle venas terciarias, areolas y vénulas. D: Epidermis en la cara adaxial. E: Cara abaxial-detalle de los estomas. Escala: A: $3 \mathrm{~cm}$., B: $1 \mathrm{~cm}$., C: 0,25 cm., D: $50 \mu \mathrm{m}$., E: $30 \mu \mathrm{m}$.

poco demarcadas y poco frecuentes; las venas $3^{\circ}$ son opuestas- alternas percurrentes, las venas $3^{\circ}$ forman un reticulado poligonal regular en toda la lámina, ramificación de la vena $3^{\circ}$ es exmedial, es decir se ramifica hacia el margen de la hoja, la vena de $4^{\circ}$ orden se anastomosan con otras venas formando un reticulado de polígonos de similar tamaño, alterno percurrentes; las venas de $5^{\circ}$ orden se anastomosan con otras venas formando un reticulado de polígonos de similar tamaño; areolas están bien desarrolladas de 4-5 a más lados, 2-3 areolas $/ \mathrm{mm}^{2}$; vénulas del último orden de venación ramificadas 2 a más veces; último orden de venación $5^{\circ}$; la última vena marginal es en arcos.

Epidermis: Estomas presentes únicamente en la cara abaxial de la lámina. Los estomas son del tipo paracítico, densidad estomática de 600-1700 
(media: 1150) estomas $/ \mathrm{mm}^{2}$, el número de células epidérmicas $/ \mathrm{mm}^{2}$ es de 4000-9700 (media: 6850) y el índice estomático es de 0,14 (14\%). Estomas poco visibles en aumento de $4 \mathrm{X}$, mientras que en $10 \mathrm{X}$ son bien perceptibles. Las células epidérmicas fundamentales en la cara adaxial al igual que en la cara abaxial son poligonales con paredes rectas.

Material de referencia: Keller \& Keller 10635 (CTES).

\section{Nectandra lanceolata Nees (Fig. 5):}

Exomorfología: Hojas estrechamente elípticas a lanceoladas, de 8 a $20 \mathrm{~cm}$ de largo y de 2,5 a 5 $\mathrm{cm}$ de ancho; de borde entero, levemente revoluto en la base de la lámina; ápice acuminado; base aguda; la cara adaxial es glabrescente y de un color verde oscuro; la cara abaxial presenta
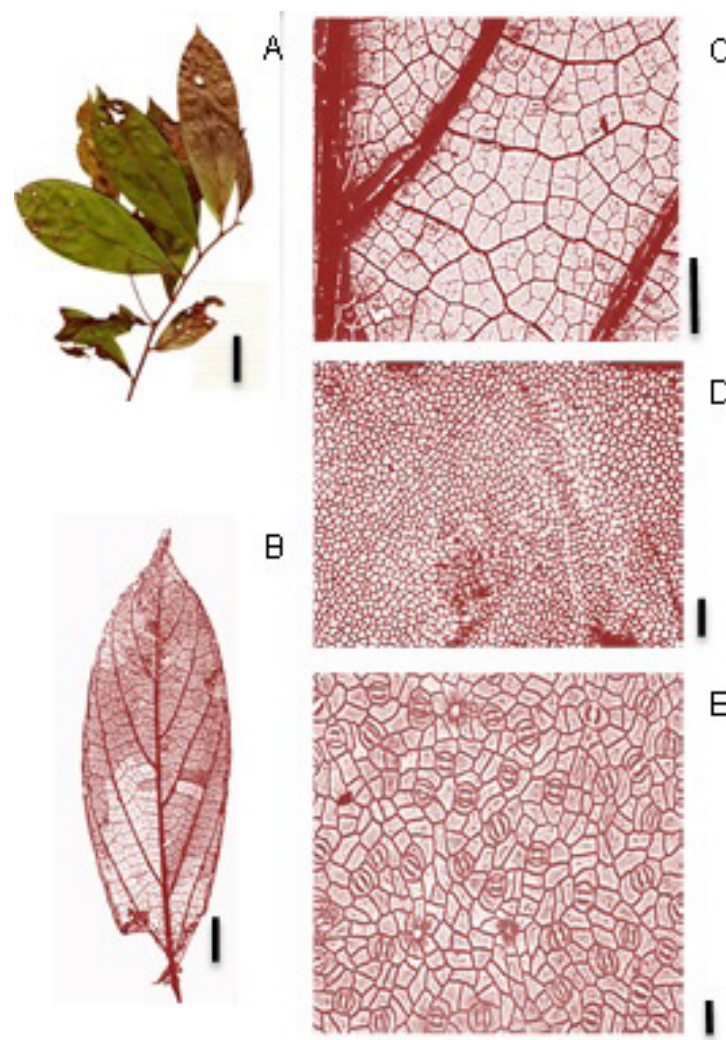

Fig. 5. Nectandra lanceolata Nees. A: Rámulo. B: Hoja diafanizada. C: Detalle venas terciarias, areolas y vénulas. D: Epidermis en la cara adaxial. E: Cara abaxial- detalle de los estomas. Escalas: A: $3 \mathrm{~cm}, \mathrm{~B}: 1 \mathrm{~cm}, \mathrm{C}: 0,5 \mathrm{~cm}, \mathrm{D}: 100 \mu \mathrm{m}, \mathrm{E}: 25 \mu \mathrm{m}$. pubescencia de color ferrugíneo; presenta en la cara abaxial domacios del tipo escrobícula sobre la vena principal; la vena principal en la cara abaxial es prominente y en la cara adaxial es inmersa; relación L: W es de 3,2:1 a 4:1. Pecíolo de 0,25 a $0,5 \mathrm{~cm}$ de diámetro y de 0 , 5 a $1,5 \mathrm{~cm}$ de largo; la posición del peciolo es marginal, pubescente de color ferruginoso, sección transversal circular a canaliculado.

Venación: La categoría de venación primaria es pinnada, la venación secundaria que presenta es eucamptódromo- broquidódroma; el espaciamiento de las venas secundarias es creciente hacia la base, de distanciamiento irregular; de 5-7 pares de venas secundarias; las venas intersecundarias son poco frecuentes; las venas $3^{\circ}$ son alterno percurrentes; la dirección que toman las venas $3^{\circ}$ es hacia el margen de la hoja; el $4^{\circ}$ orden de venación forma un reticulado de polígonos regulares, alternos-percurrentes; el $5^{\circ}$ orden de venación forma un reticulado poligonal regular, las venas del $5^{\circ}$ orden se anastomosan con otras venas del mismo orden para formar polígonos de similar tamaño y forma; las areolas están bien desarrolladas (definidas) de 4-5 o más lados, 1- 2 areolas $/ \mathrm{mm}^{2}$; el ultimo orden de venación terminan con 2 a más ramificaciones; la última vena marginal es en arcos.

Epidermis: Estomas presentes únicamente en la cara abaxial de la lámina; estomas tipo paracítico. Número de estomas por milímetro cuadrado es de 400-1200 (media: 800) estomas/ $\mathrm{mm}^{2}$, el número de células epidérmicas por milímetro cuadrado es de 2000-4000 (media: 3000) y el índice estomático es de 0,21 (21\%). Estomas bien visibles con un aumento de $4 \mathrm{X}$ y de 10X. Las células epidérmicas fundamentales en la cara adaxial como en la cara abaxial son poligonales con paredes rectas.

Material de referencia: Tressens et al. 4650 (CTES).

Nectandra megapotamica (Spreng.) Mez (Fig. 6):

Exomorfología: Hojas estrechamente elíptica, alternas, de 5 a $15 \mathrm{~cm}$ de largo y de 2,5 a $3,5 \mathrm{~cm}$ de ancho; de borde entero; ápice acuminado, base decurrente y simétrica; cara adaxial glabra, cara abaxial glabrescente en la lámina y con algunos pelos en la vena primaria; relación L:W (largo:ancho) de 4,5:1 a 5:1; no presentan 


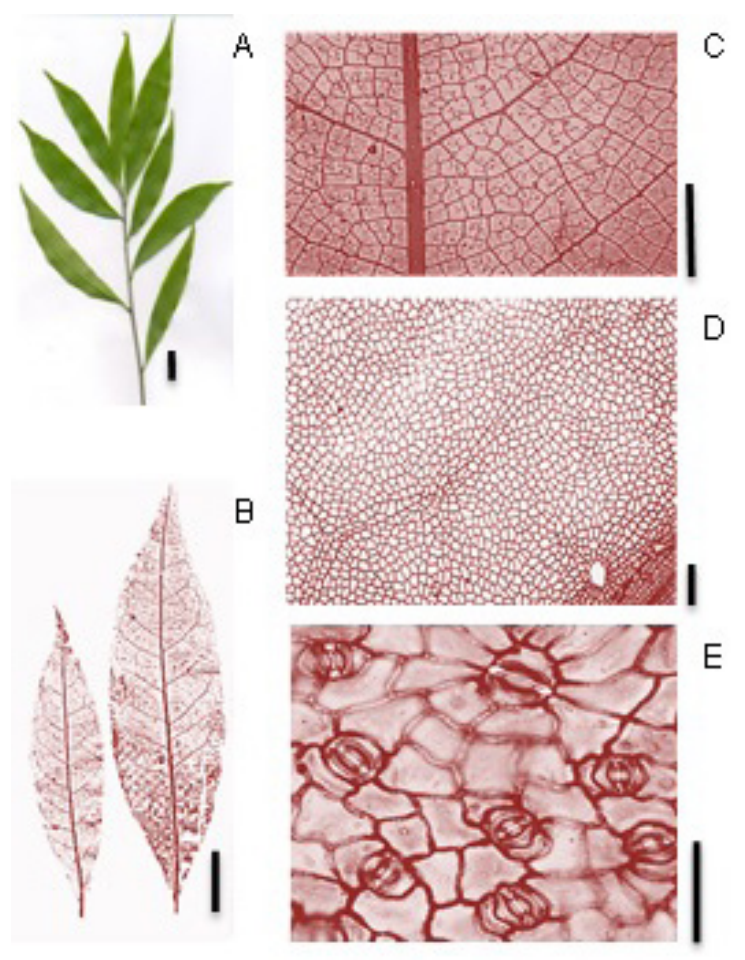

Fig. 6. Nectandra megapotamica (Spreng.) Mez. A: Rámulo. B: Hoja diafanizada. C: Detalle venas terciarias, areolas y vénulas. D: Epidermis en la cara adaxial. E: Cara abaxial-detalle de los estomas. Escala: A: $2 \mathrm{~cm}$., B: $2 \mathrm{~cm}$., C: $0,5 \mathrm{~cm}$, D: $100 \mu \mathrm{m} ., \mathrm{E}: 15 \mu \mathrm{m}$.

domacios. Pecíolo de 0,5- $1 \mathrm{~cm}$ de largo, glabrescente, sección trasversal canaliculado.

Venación: Orden de venación $1^{\circ}$ de tipo pinnada; $2^{\circ}$ categoría de venación broquidódroma, 8- 12 pares de venas $2^{\circ}$, el espaciamiento de las venas $2^{\circ}$ es regular; venas intersecundarias presentes; vena de $3^{\circ}$ categoría son opuestosalternos percurrentes (mix op/alt), las venas $3^{\circ}$ se anastomosan con otras venas formando polígonos regulares, el curso que toman las venas $3^{\circ}$ sinuoso, se ramifican exmedialmente; la $4^{\circ}$ categoría de venación se anastomosan con otras venas formando un reticulado de polígonos regulares, alternos-percurrentes; la $5^{\circ}$ categoría de venación se anastomosan con otras venas formando un reticulado de polígonos de similar tamaño y forma; las areolas están bien desarrolladas y poseen 4-5 lados, 1-2 areolas/ $\mathrm{mm}^{2}$; vénulas se ramifican de 2 a más veces tipo dendríticas; último orden de venación $5^{\circ}$; última vena marginal en arcos.

Epidermis: Estomas presentes solamente en la cara abaxial, la cara adaxial no presenta estomas. Estomas del tipo parasítico; densidad estomática por milímetro cuadrado 600-1700 (media: 1150) estomas $/ \mathrm{mm}^{2}$, el número de células epidérmicas/ $\mathrm{mm}^{2}$ es de 4000-9900 (media: 6950), el índice estomático 0,14 (14\%). Estomas bien visibles con un aumento de 4X y en 10X. Las células epidérmicas fundamentales en la cara adaxial son poligonales mientras que en la cara abaxial son poligonales con paredes rectas.

Material de referencia: Tressens et al. 5409 (CTES).

Ocotea acutifolia (Nees) Mez (Fig.7):

Exomorfología: Hojas estrechamente elípticas, de 4 a 7,5 cm de largo y de 1,5 a 2,5 cm de ancho, borde entero, ápice agudo a levemente acuminado; base cuneada, simétrica a levemente asimétrica; superficie adaxial glabrescente, nervadura primaria glabrescente, vistosa de color amarillento, algo prominente en el tercio inferior de la lámina; cara abaxial glabrescente, nervadura primaria algo prominente; no presenta domacios; relación L:W (largo: ancho) 3:1 a 5:1. Pecíolo de $1-2 \mathrm{~cm}$ de largo, glabrescente, de color amarillo crema, sección transversal bilobulado- acanalado.

Venación: Orden de venación $1^{\circ}$ es pinnada; $2^{\circ}$ orden de venación del tipo craspedódromo, 45 pares de venas $2^{\circ}$; espaciamiento de las venas secundarias es irregular, venas intersecundarias poco presentes; $3^{\circ}$ orden de venación alterno percurrentes de ramificación exmedial; $4^{\circ}$ orden de venación formando un reticulado de polígonos regulares, alterno percurrentes; $5^{\circ}$ orden de venación formando un reticulado de polígonos regulares; areolas de 4- 5, 1- 2 areolas $/ \mathrm{mm}^{2}$; vénulas del tipo dendríticas; última categoría de venación $5^{\circ}$; última vena marginal del tipo fimbrial.

Epidermis: Estomas presentes únicamente en la cara abaxial de la lámina. Estomas del tipo paracítico. Número de estomas por milímetro 


\section{P. A. Poszkus Borrero et al. - Arquitectura foliar de Lauraceae de Misiones}
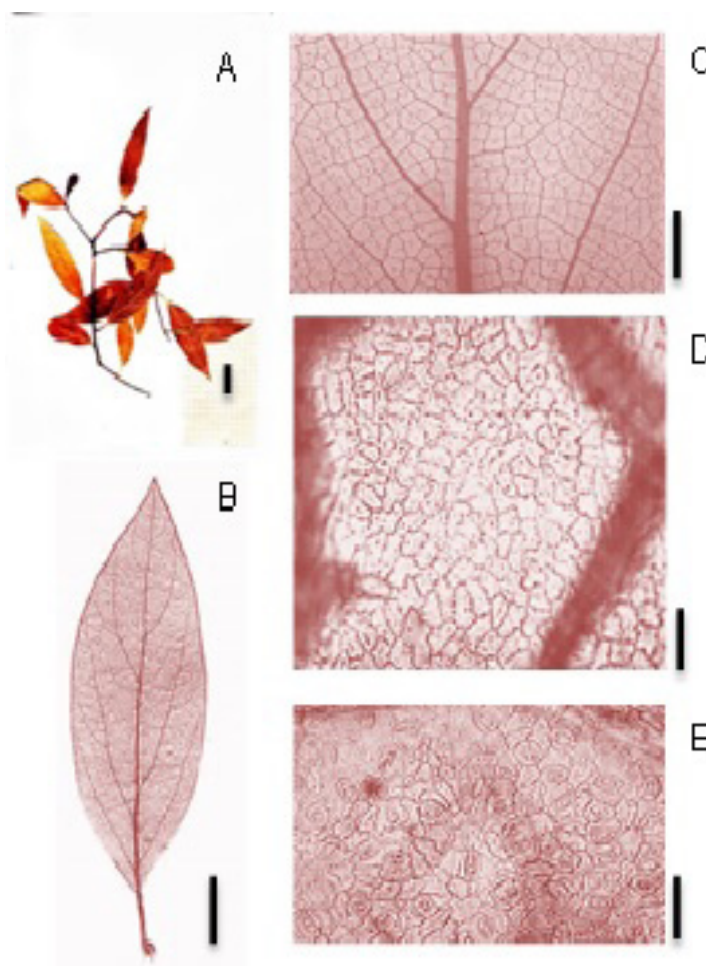

Fig. 7. Ocotea acutifolia (Nees) Mez. A: Rámulo. B: Hoja diafanizada. C: Detalle venas terciarias, areolas y vénulas. D: Epidermis en la cara adaxial. E: Cara abaxial- detalle de los estomas. Escala: A: 2 cm., B: $1 \mathrm{~cm} ., \mathrm{C}: 0,5 \mathrm{~cm}$., E: $50 \mu \mathrm{m}$., F: $50 \mu \mathrm{m}$.

cuadrado de 800-1200 (media: 1000) estomas/ $\mathrm{mm}^{2}$, el número de células epidérmicas $/ \mathrm{mm}^{2}$ es de 2000-4000 (media: 3000) y el índice estomático es de $0,25(25 \%)$. Estomas poco visibles con aumento de 10X. Las células epidérmicas fundamentales en la cara adaxial son poligonales con paredes onduladas mientras que en la cara abaxial son poligonales con paredes suavemente onduladas.

Material de referencia: Keller \& Krauczuk 11297 (CTES).

Ocotea diospyrifolia (Meisn.) Mez (Fig. 8):

Exomorfología: Hojas elípticas a estrechamente elípticas, borde algo ondulado, de $3-10 \mathrm{~cm}$ de largo y de 1,5-2,5 cm de ancho; ápice acuminado, base atenuada; superficie adaxial glabra, nervadura principal inmersa; superficie abaxial glabra, con nervaduras primarias y secundarias prominentes;
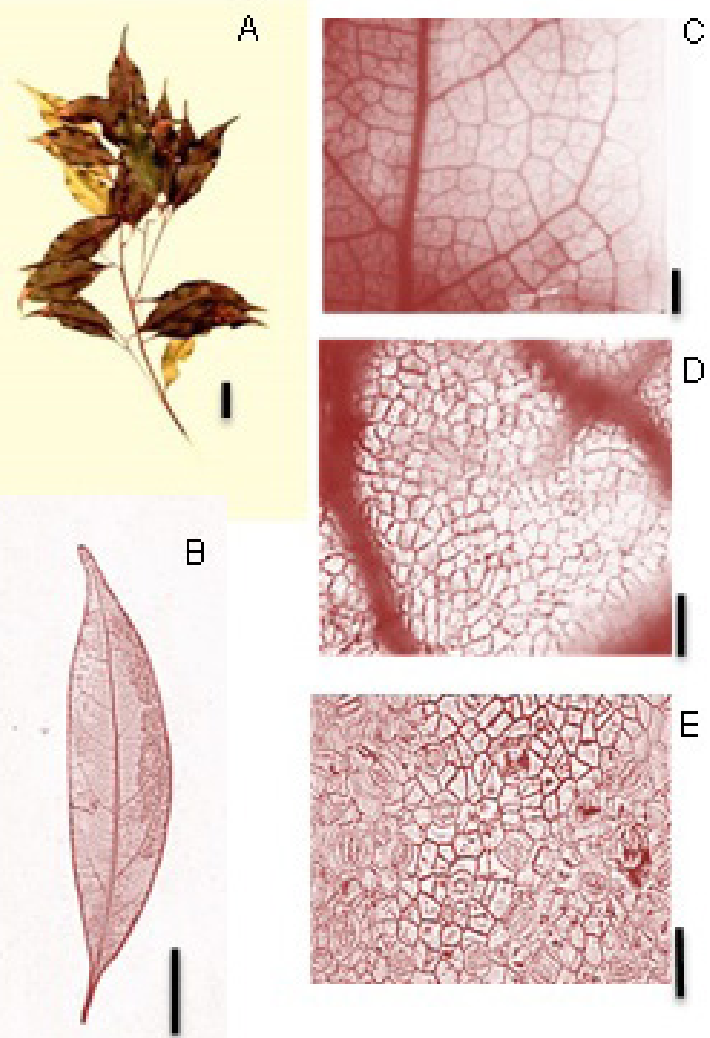

Fig. 8. Ocotea diospyrifolia (Meisn.) Mez. A: Rámulo. B: Hoja diafanizada. C: Detalle de las venas terciarias, areolas y vénulas. D: Epidermis en la cara adaxial. E: Cara abaxial- detalle de los estomas. Escala: A: $2 \mathrm{~cm}$., B: $2 \mathrm{~cm}$., C: $1 \mathrm{~mm}$., D: 30 $\mu \mathrm{m} ., \mathrm{E}: 30 \mu \mathrm{m}$.

sin domacios; relación L:W (largo: ancho) 2:1 a 4:1. Pecíolo de 0,5 a $1 \mathrm{~cm}$ de largo, glabrescente, sección transversal canaliculado.

Venación: Primer orden de venación pinnada; $2^{\circ}$ orden de venación broquidódroma, 6-5 pares de nervaduras secundarias, espaciamiento entre las venas secundarias es irregular; venas intersecundarias poco frecuentes; $3^{\circ}$ orden de venación alterno percurrentes, el curso de las venas terciaras es sinuoso, de ramificación exmedial, $4^{\circ}$ orden de venación alterno percurrentes, formando un reticulado de polígonos regulares; $5^{\circ}$ orden de venación formando retículos regulares; areolas bien formadas, de 4-5 lados, 1-2 areolas $/ \mathrm{mm}^{2}$; vénulas dendríticas; ultimo orden de venación $5^{\circ}$; ultima vena marginal en arcos. 
Epidermis: Estomas presentes únicamente la cara abaxial de la lámina; estomas del tipo paracítico. El número de estomas por milímetro cuadrado es de 400-1200 (media: 800) estomas/ $\mathrm{mm}^{2}$, el número de células epidérmicas por $\mathrm{mm}^{2}$ es de 4000-7300 y el índice estomático es de $0,12(12 \%)$. Estomas bien visibles con aumentos de 10X. Las células epidérmicas fundamentales en la cara adaxial como en la cara abaxial son poligonales con paredes rectas.

Material de referencia: Tressens et al. 6468. (CTES).

\section{Ocotea lancifolia (Schott) Mez (Fig. 9):}

Exomorfología: Hojas elípticas a oblanceoladas, alternas, de 3 a 10,5 cm de largo y de 1 a 2,5 cm de ancho, de borde entero; ápice agudo, base asimétrica; cara adaxial glabrescente y cara abaxial glabra; relación largo-ancho $(\mathrm{L}: \mathrm{W})$ de

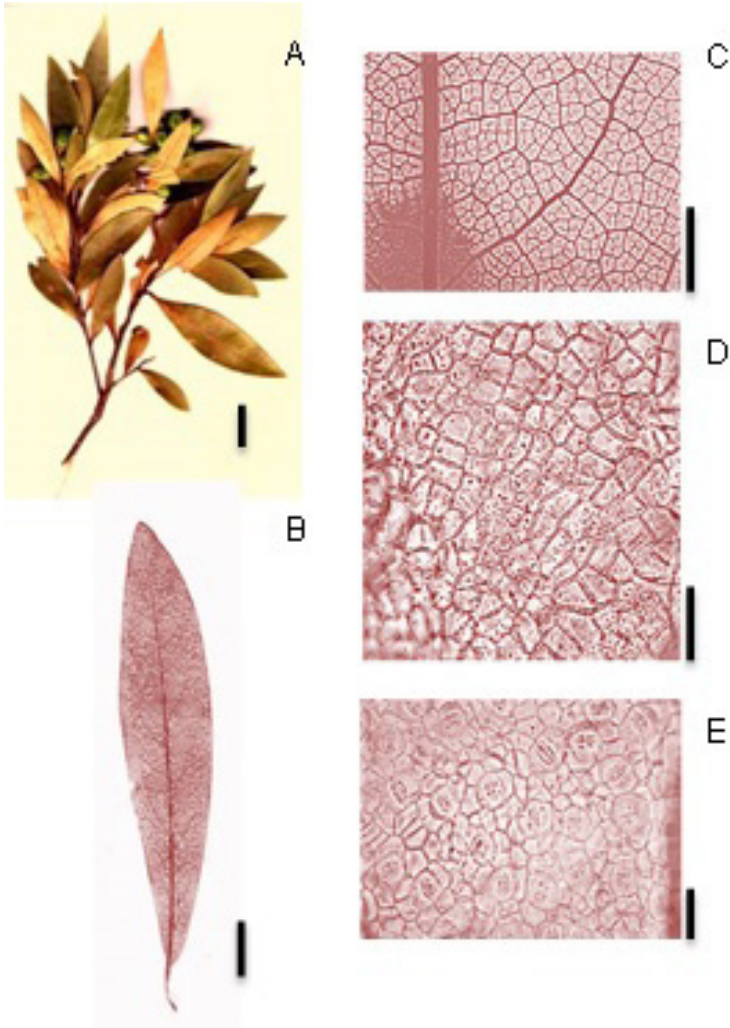

Fig. 9. Ocotea lancifolia (Schott) Mez. A: Rámulo. B: Hoja diafanizada. C: Detalle de las venas terciarias, aréolas y vénulas. D: Epidermis en la cara adaxial. E: Cara abaxial- detalle de los estomas. Escala: A: $2 \mathrm{~cm}$., B: $1 \mathrm{~cm}$., C: 0,5 cm., D: $30 \mu \mathrm{m} ., \mathrm{E}: 30 \mu \mathrm{m}$.
3:1 a 4:1; no presenta domacios. Pecíolo de 0,5- 1 $\mathrm{cm}$ de largo, glabrescente, color negruzco, sección transversal bilobulado.

Venación: El $1^{\circ}$ orden de venación es pinnada; $2^{\circ}$ orden de venación es eucantódromobroquidódroma; 7-10 pares de venas secundarias; el espaciamiento entre las venas secundarias es regular, venas intersecundarias poco frecuentes; $3^{\circ}$ orden de venación alterno percurrentes, el curso de las venas $3^{\circ}$ es sinuoso ramificándose exmedialmente, alterno percurrentes; $4^{\circ}$ orden de venación se anastomosan para formar un reticulado regular, alterno percurrentes; $5^{\circ}$ orden de venación se anastomosan con otras venas formando un reticulado regular; areolas de 4-5 lados; 1-2 areolas/ $\mathrm{mm}^{2}$; vénulas dendríticas; ultimo orden de venación $5^{\circ}$; ultima vena marginal en arcos.

Epidermis: Estomas presentes únicamente en la cara abaxial de la lámina; estomas del tipo paracítico. Número de estomas por milímetro cuadrado es de 400-800 (media: 600) estomas/ $\mathrm{mm}^{2}$, el número de células epidérmicas por $\mathrm{mm}^{2}$ es de 3600-4300 (media: 3950) y el índice estomático es de $0,13(13 \%)$. Estomas visibles a 10X. Las células epidémicas en la cara adaxial como en la abaxial son poligonales con paredes rectas.

Material de referencia: Keller \& Franco 5656 (CTES).

\section{Ocotea puberula (Rich) Nees (Fig. 10):}

Exomorfología: hojas elípticas lanceoladas; de 6 a $18 \mathrm{~cm}$ de largo y de 2 a $4 \mathrm{~cm}$ de ancho; ápice acuminado; base aguda; borde revoluto en la base de la lámina; cara adaxial glabra y de color verde oscuro; cara abaxial glabrescente con una tonalidad de verde claro; nervadura primaria plana en la cara adaxial de color amarillento; la nervadura primaria es saliente en la cara abaxial; no presenta domacios, relación L:W (largo:ancho) de 3:1 a 4,5:1. Pecíolo de 1 a 2,5 cm de largo, sección transversal semicircular subcanaliculado.

Venación: Primer orden de venación del tipo pinnada, segundo orden de venación tipo broquidódromo; de 8 a 16 venas secundarias de cada lado de la primaria, con distanciamiento regular; nervaduras terciarias alterno-opuestas, $4^{\circ}$ orden de venación alterno percurrentes; $5^{\circ}$ orden de venación se anastomosan con otras venas formando un retículo de polígonos regulares; areolas de 4-5 a más lados, 2-3 areolas $/ \mathrm{mm}^{2}$; vénulas ramificadas 


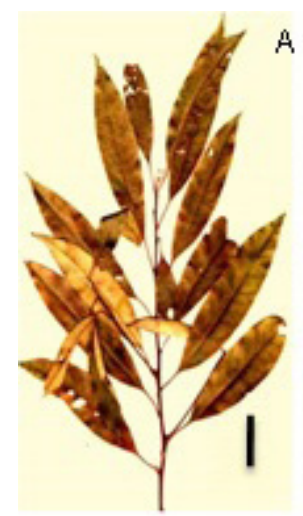

$\mathrm{B}$
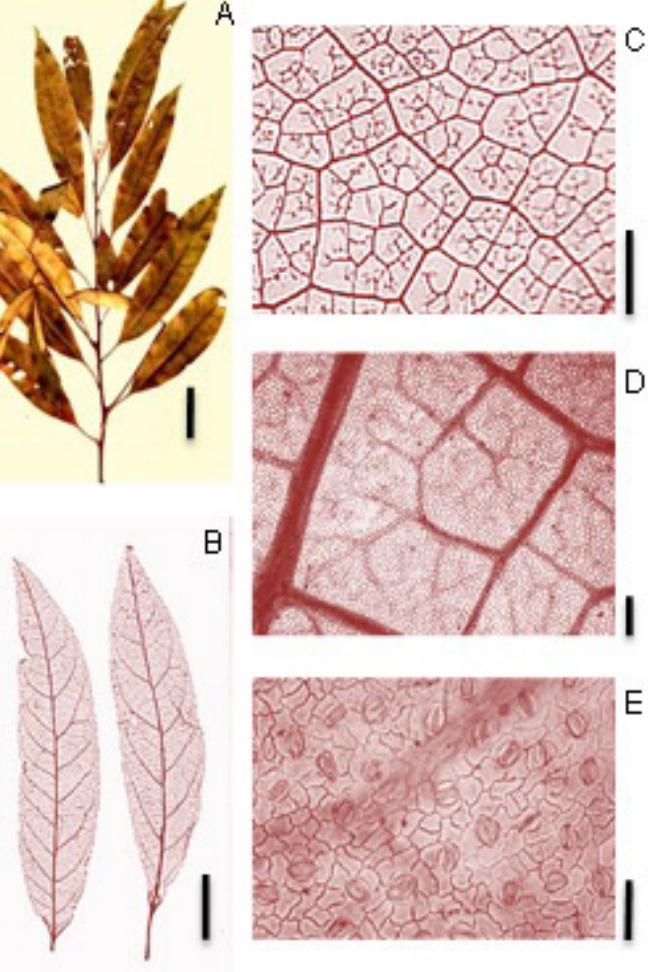

Fig. 10. Ocotea puberula (Rich) Nees. A: Rámulo. B: Hoja diafanizada. C: Detalle venas terciarias, areolas y vénulas. D: Epidermis en la cara adaxial. E: Cara abaxial-detalle de los estomas. Escala: A: 3 cm., B: 2 cm., C: 1mm., D: $100 \mu \mathrm{m} .$, E: $30 \mu \mathrm{m}$.

más de 2 veces (dendríticas); último orden de venación $5^{\circ}$; vena marginal tipo fimbrial.

Epidermis: Estomas presentes solo en la cara abaxial de la lámina; estomas del tipo paracítico con dos células anexas. Densidad estomática 800-1000 (media: 900) estomas $/ \mathrm{mm}^{2}$, el número de células epidérmicas por $\mathrm{mm}^{2}$ es de 4000-8400 (media: 6200) y el índice estomático es de 0,13 (13\%). Estomas bien visibles en aumentos de $4 \mathrm{X}$ y 10X. Células epidérmicas fundamentales en la cara adaxial son poligonales con paredes rectas, mientras que en la cara abaxial son poligonales con paredes onduladas.

Material de referencia: Tressens et al. 5658 (CTES).

Ocotea pulchella (Nees) Mez (Fig. 11):

Exomorfología: Hojas ovadas, lanceoladas a elíptica, filotaxis alterna, de 3,5 a $7,5 \mathrm{~cm}$ de

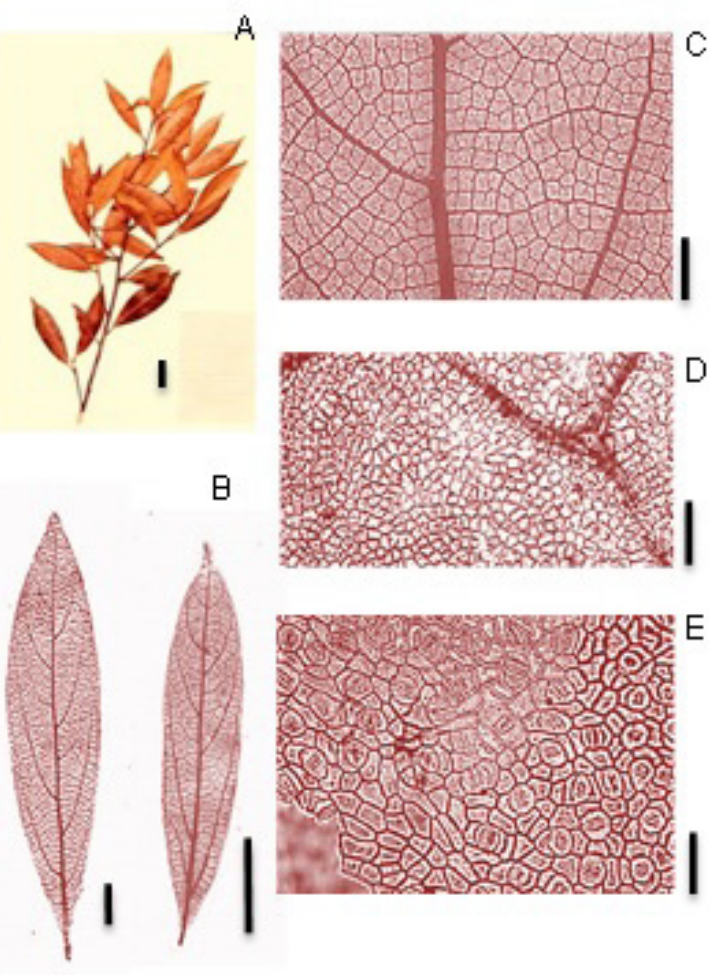

Fig. 11. Ocotea pulchella (Nees) Mez. A: Rámulo. B: Hoja diafanizada. C: Detalle de las venas terciarias, aréolas y vénulas. D: Epidermis en la cara adaxial. E: Cara abaxial- detalle de los estomas. Escala: A: 2 $\mathrm{cm}, \mathrm{B}: 2 \mathrm{~cm}, \mathrm{C}: 0,5 \mathrm{~cm}, \mathrm{D}: 50 \mu \mathrm{m}, \mathrm{E}: 30 \mu \mathrm{m}$.

largo y de 1 a $2,5 \mathrm{~cm}$ de ancho; borde entero, ápice acuminado; base cuneada, simétrica; superficie adaxial glabrescente, color verde oscuro, nervadura primaria glabrescente; cara abaxial algo pubescente, verde claro, nervadura primaria prominente y con pubescencia; presenta domacios del tipo escrobícula; relación $\mathrm{L}: \mathrm{W}$ (largo: ancho) 3:1 a 5:1. Pecíolo de 0,5- $1 \mathrm{~cm}$ de largo, laxamente velloso, sección transversal semicircular- bilobulado.

Venación: orden de venación $1^{\circ}$ pinnada, $2^{\circ}$ orden de venación del tipo acródromo suprabasal imperfecto-broquidódroma; 5-8 pares de venas secundarias; el espaciamiento entre las venas secundarias es irregular; venas intersecundarias poco presentes; $3^{\circ}$ orden de venación alternas percurrente, el curso de la vena $3^{\circ}$ es sinuoso, $4^{\circ}$ orden de venación formando un reticulado con polígonos regulares, alterno percurrentes; 
$5^{\circ}$ orden de venación formando un reticulado de polígonos regulares; areolas de 4- 5 o más lados; 1-2 areolas $/ \mathrm{mm}^{2}$; vénulas dendríticas; último orden de venación $5^{\circ}$; ultima vena marginal en arcos.

Epidermis: Estomas presentes únicamente en la cara abaxial de la lámina. Estomas tipo paracíticos. El número de estomas por milímetro cuadrado es de 600-1800 (media: 1200) estomas/ $\mathrm{mm}^{2}$, el número de células epidérmicas por $\mathrm{mm}^{2}$ es de 4000-8000 y el índice estomático es de $0,16(16 \%)$. Estomas visibles en aumentos de 10X. Las células epidérmicas fundamentales en la cara adaxial al igual que en la cara abaxial son poligonales de paredes rectas.

Material de referencia: Tressens et al. 5120 (CTES).

\section{Ocotea sp. (Fig. 12):}

Exomorfología: Hojas elípticas a oblanceoladas, alternas; de 5 a $11 \mathrm{~cm}$ de largo y de 2,5 a $4 \mathrm{~cm}$ de ancho; ápice cortamente acuminado, base decurrente; borde entero suavemente ondulado; cara adaxial glabrescente, cara abaxial glabrescente sobre la lámina, presenta domacios en el envés dispuestos a lo largo de la vena primara ocupando $1 / 3$ de la longitud de esta en la parte inferior de la hoja de color blanquecino a ferruginoso; relación L:W (largo: ancho ) 2:1 a 3:1; al ser estrujada la hoja emite un olor fétido. Pecíolo de 0,5-1,5 cm de largo, algo pubescente, sección transversal canaliculado- acanalado.

Venación: venación de $1^{\circ}$ orden es pinnada; $2^{\circ}$ orden de venación broquidódroma, 10-18 pares de venas secundarias, espaciamiento de las venas secundarias es regular, venas intersecundarias pocas; $3^{\circ}$ orden de venación alterno percurrentes, curso de la vena sinuoso de ramificación exmedialmente, $4^{\circ}$ orden de venación se anastomosan formando polígonos de similar tamaño, alternos percurrentes; $5^{\circ}$ orden de venación reticulado poligonal regular; areolas de 4- 5 a más lados; 1-2 areolas $/ \mathrm{mm}^{2}$; vénulas dendríticas; ultimo orden de venación $5^{\circ}$; ultima vena marginal tipo fimbrial.

Epidermis: Estomas únicamente presentes en la cara abaxial de la lámina. Estomas del tipo paracítico. El número de estomas por milímetro cuadrado es de 600-1600 (media: 1100) estomas/

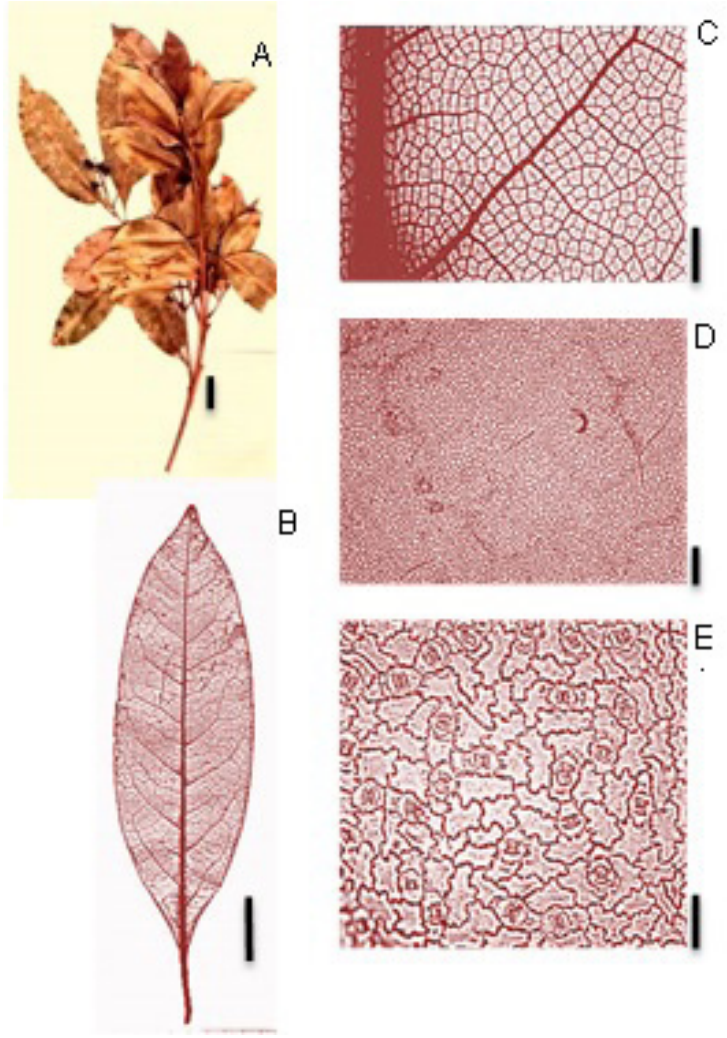

Fig. 12. Ocotea sp. A: Rámulo. B: Hoja diafanizada. C: Detalle de las venas terciarias, arólas y vénulas. D: Epidermis en la cara adaxial. E: Cara abaxialdetalle de los estomas. Escala: A: $2 \mathrm{~cm}, \mathrm{~B}: 3 \mathrm{~cm}$, C: 0,5 cm, D: $100 \mu \mathrm{m}, \mathrm{E}: 25 \mu \mathrm{m}$.

$\mathrm{mm}^{2}$, el número de células por $\mathrm{mm}^{2}$ es de 3000 4933 (media: 3967) y el índice estomático es $0,21(21 \%)$. Estomas poco visibles a $4 \mathrm{X}$ y a $10 \mathrm{X}$. Las células epidérmicas fundamentales en la cara abaxial poligonales con paredes fuertemente onduladas, mientras que en la cara adaxial las paredes son suavemente onduladas.

Material de referencia: Keller et al. 10365 (CTES).

A partir del análisis de cada especie se olcó en la Tabla 2, Tabla 3 y Tabla 4 las características más relevantes de cada una de ellas (ver Apéndice).

En base a las características distintivas de las especies estudiadas se elaboró la Clave para la identificación de cada una de las Lauraceae de la Selva Misionera- Argentina que se presenta a continuación. 


\section{Clave basada en caracteres foliares para las especies de Lauraceae de la Selva Misionera}

1 Hojas con domacios

2 Venación secundaria broquidódroma.

Ocotea sp.

2' Venación secundaria eucantódromo- broquidódromo o acródromo suprabasal imperfectobroquidódromo.

3 Venación secundaria tipo eucantódromo-broquidódroma.

Nectandra lanceolada

3' Venación secundaria tipo acródroma suprabasal imperfecto-broquidódroma.

4 Ápice foliar cortamente acuminado, 4-5 pares de venas secundarias, de 5-12 cm de largo y de 2-3,5 cm de ancho, 2-4 areolas/mm2, última vena marginal fimbrial.

Cinnamomum amoenum

4' Ápice foliar acuminado, 5-8 pares de venas secundarias, de 3,5-7,5 cm de longitud y de 1-2,5 $\mathrm{cm}$ de ancho, 1-2 areolas/mm2, última vena marginal en arcos.

Ocotea pulchella

1' Hojas sin domacios.

5 Venación secundaria broquidódroma.

6 Hojas pubescentes, 3-7 cm de latitud, 2-3 areolas $/ \mathrm{mm} 2$.

6' Hojas glabrescente, de 2- $4 \mathrm{~cm}$ de latitud, 1 a 2 areolas $/ \mathrm{mm} 2$.

Endlicheria paniculata

7 Peciolo de 1-2,5 cm de longitud.

7' Pecíolos menores a $1 \mathrm{~cm}$ de longitud.

Ocotea puberula

8 Láminas con 7-12 pares de venas secundarias

9 Ápice acuminado, venas de $3^{\circ}$ orden alterno-percurrentes, vénulas ramificadas más de dos veces; última vena marginal en arcos.

Nectandra megapotamica

9' Ápice cortamente acuminado, venas de $3^{\circ}$ orden alterno-subopuestos percurrentes, vénulas simples a ramificadas una vez; última vena marginal tipo fimbrial.

8' Láminas con 5-6 pares de venas secundarias

Cryptocaria aschersoniana

Ocotea diospyrifolia

5' Venación secundaria craspedódroma o eucantódromo-broquidódromo.

10 Venación secundara craspedódroma.

Ocotea acutifolia

10' Venación secundaria eucantódromo-broquidódroma.

11 Hojas linear lanceoladas, 7-12 veces más larga que ancha.

11' Hojas elíptico oblanceoladas , 3-4 veces más larga que ancha

Nectandra angustifolia

Ocotea lancifolia 
Bol. Soc. Argent. Bot. 51 (1) 2016

\begin{tabular}{|c|c|c|c|c|c|c|c|c|}
\hline 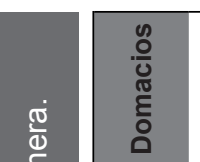 & 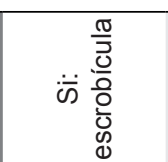 & zo & zo & zo & 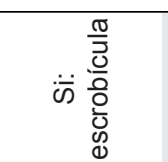 & zo & z & zo \\
\hline 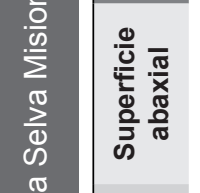 & 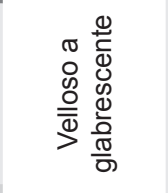 & $\frac{\frac{\pi}{2}}{\frac{\pi}{10}}$ & 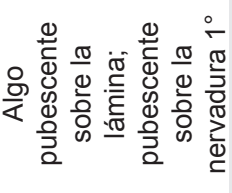 & 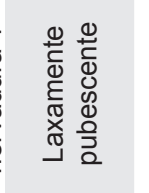 & 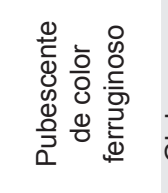 & 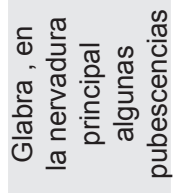 & $\frac{\frac{\pi}{0}}{\frac{\pi}{0}}$ & $\frac{\frac{\pi}{0}}{\frac{\pi}{\pi}}$ \\
\hline $\begin{array}{l}\frac{0}{0} \\
\frac{\pi}{\frac{\pi}{x}} \\
\frac{\pi}{x} \\
\frac{0}{5} \frac{\pi}{\sigma} \\
\omega\end{array}$ & $\begin{array}{l}\frac{\pi}{0} \\
\frac{\pi}{0}\end{array}$ & $\frac{\pi}{\frac{\pi}{0}}$ & 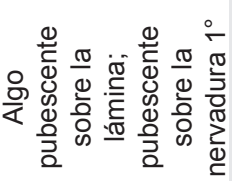 & $\frac{\frac{\pi}{0}}{\frac{\pi}{0}}$ & $\begin{array}{l}\frac{\pi}{0} \\
\frac{\pi}{0}\end{array}$ & $\begin{array}{l}\frac{\pi}{\frac{0}{\pi}} \\
\frac{\pi}{10}\end{array}$ & $\begin{array}{l}\frac{\pi}{0} \\
\frac{\pi}{0}\end{array}$ & $\begin{array}{l}\frac{\pi}{\frac{\pi}{0}} \\
\frac{\pi}{10}\end{array}$ \\
\hline$\frac{5}{\frac{\pi}{20}}$ & 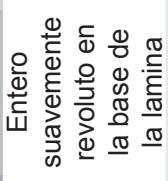 & 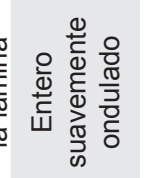 & 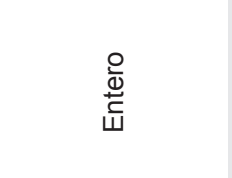 & 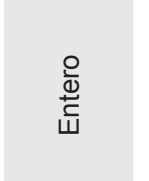 & 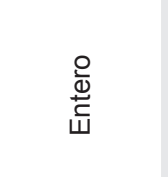 & 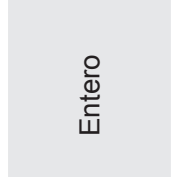 & 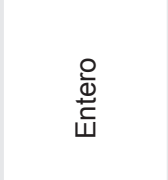 & 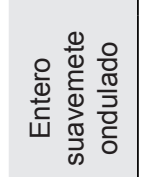 \\
\hline 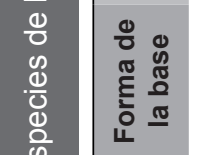 & $\begin{array}{l}\frac{\pi}{0} \\
\frac{0}{8}\end{array}$ & $\begin{array}{l}\frac{\pi}{2} \\
\mathbb{8} \\
\stackrel{0}{ \pm} \\
\frac{5}{5} \\
0\end{array}$ & $\begin{array}{l}\frac{\pi}{0} \\
\mathbb{0} \\
\stackrel{\mathbb{N}}{5} \\
0 \\
0\end{array}$ & $\begin{array}{l}\frac{\pi}{0} \\
\mathbb{8} \\
\stackrel{8}{ \pm} \\
5 \\
0\end{array}$ & $\begin{array}{l}\frac{\pi}{0} \\
\frac{0}{8}\end{array}$ & 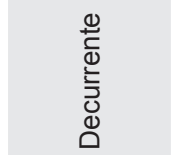 & 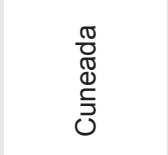 & $\begin{array}{l}\frac{\pi}{0} \\
\frac{\pi}{2} \\
\frac{1}{0} \\
\frac{d}{4}\end{array}$ \\
\hline 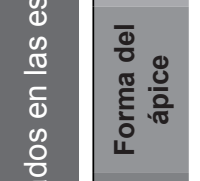 & 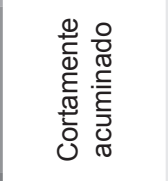 & 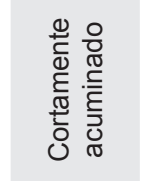 & 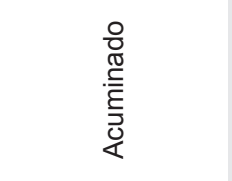 & 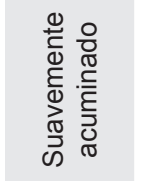 & 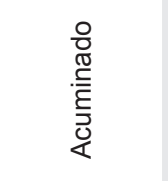 & 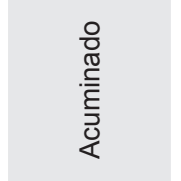 & 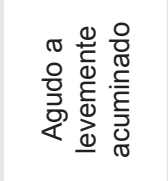 & $\begin{array}{l}\frac{0}{0} \\
\frac{\pi}{0} \\
. \frac{\pi}{5} \\
\frac{3}{4} \\
\frac{0}{4}\end{array}$ \\
\hline 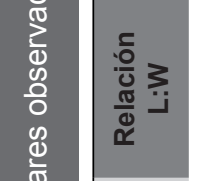 & 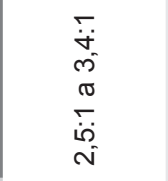 & 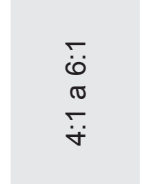 & $\begin{array}{l}\bar{i} \\
\sigma \\
\bar{i}\end{array}$ & 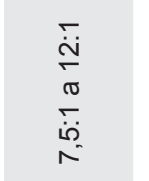 & 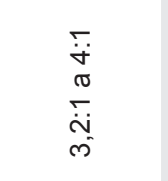 & 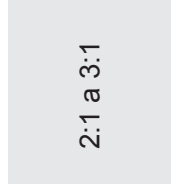 & $\begin{array}{l}\bar{i} \\
\sigma \\
\bar{\oplus}\end{array}$ & 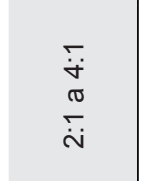 \\
\hline 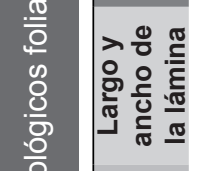 & 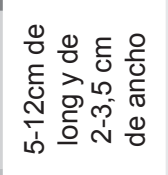 & 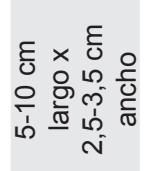 & 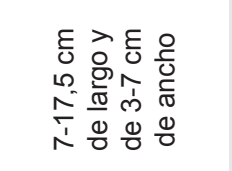 & 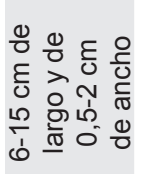 & 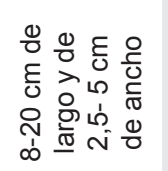 & 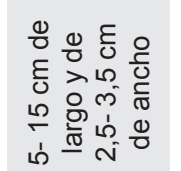 & 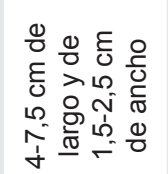 & 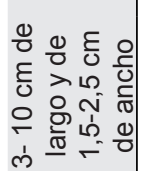 \\
\hline 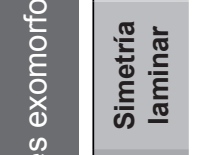 & 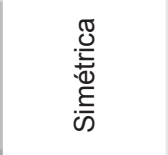 & 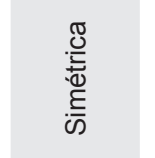 & 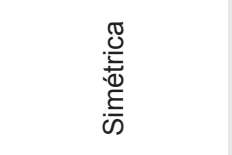 & 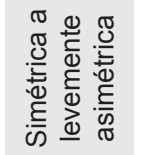 & 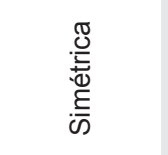 & 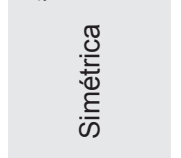 & 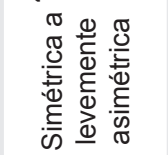 & 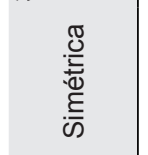 \\
\hline 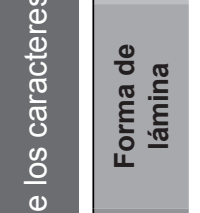 & 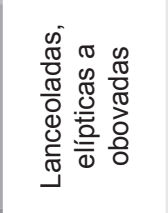 & 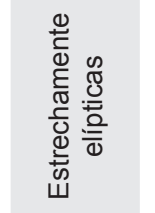 & 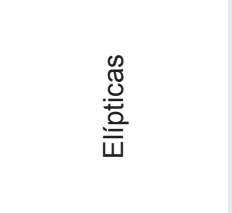 & 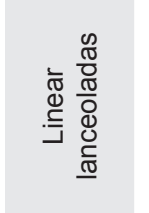 & 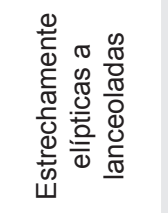 & 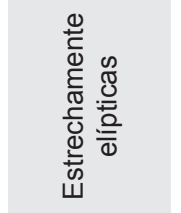 & 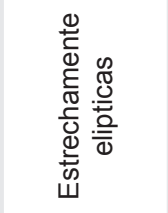 & 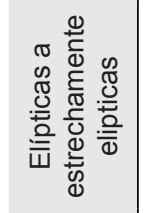 \\
\hline 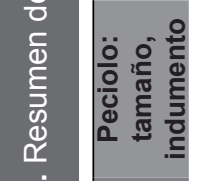 & 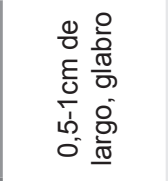 & 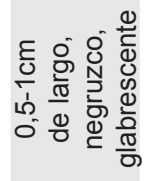 & 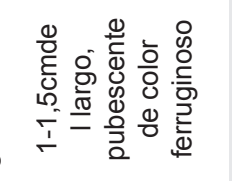 & 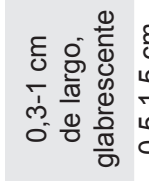 & 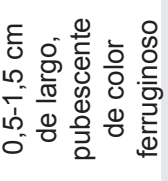 & 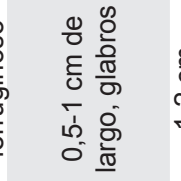 & 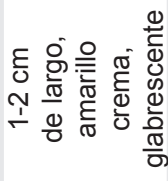 & 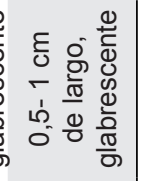 \\
\hline 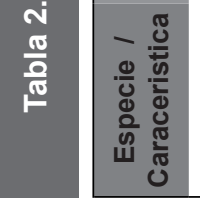 & 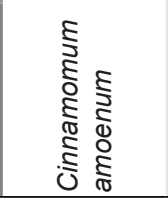 & 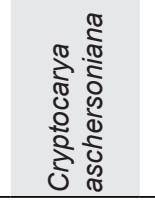 & 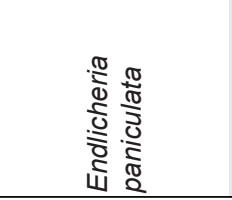 & 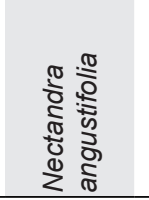 & 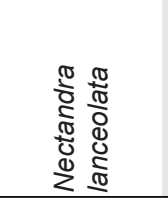 & 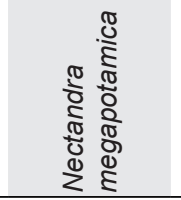 & 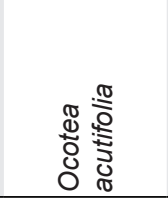 & 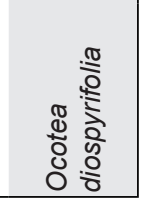 \\
\hline
\end{tabular}




\begin{tabular}{|c|c|c|c|c|}
\hline : & zo & ż & \begin{aligned} &$\frac{\pi}{J} \\
&$\hdashline$\overline{0} \frac{0}{0} \\
& \frac{0}{0} \\
& \frac{0}{0} \\
& 0 \\
& 0\end{aligned}$ & $\therefore \frac{\frac{\pi}{5}}{\frac{0}{0}}$ \\
\hline 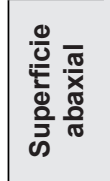 & $\frac{\frac{\pi}{2}}{\frac{\pi}{\pi}}$ & $\frac{\frac{\pi}{\frac{\pi}{0}}}{\frac{\pi}{10}}$ & 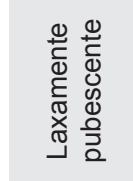 & 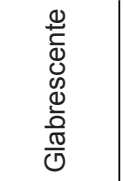 \\
\hline $\begin{array}{l}\frac{0}{0} \\
\frac{\pi}{\frac{\pi}{x}} \\
\frac{\pi}{\pi} \\
\text { 윽 } \\
\text { क }\end{array}$ & $\frac{\pi}{\frac{\pi}{0}}$ & $\begin{array}{l}\frac{\pi}{\frac{\pi}{0}} \\
\frac{\pi}{10}\end{array}$ & $\frac{\frac{\pi}{0}}{\frac{\pi}{\pi}}$ & 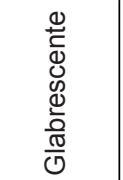 \\
\hline 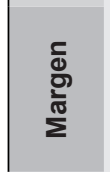 & 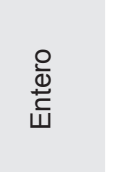 & 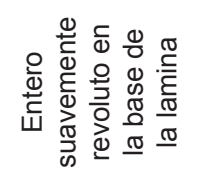 & 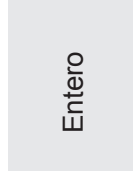 & 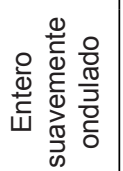 \\
\hline 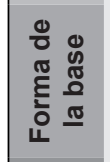 & 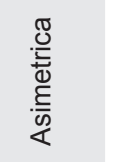 & $\begin{array}{l}\frac{\pi}{0} \\
\frac{3}{8} \\
\frac{8}{4}\end{array}$ & $\begin{array}{l}\frac{\pi}{0} \\
\mathbb{0} \\
\mathbb{1} \\
\stackrel{0}{7} \\
0\end{array}$ & 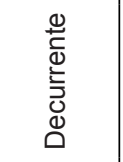 \\
\hline 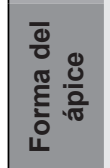 & $\begin{array}{l}\circ \\
\frac{0}{0} \\
\frac{8}{8}\end{array}$ & 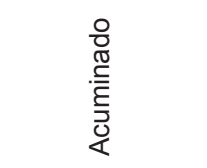 & 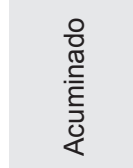 & 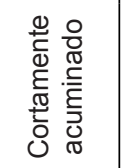 \\
\hline $\begin{array}{l}\frac{5}{0} \\
\frac{0}{0} \\
\frac{\pi}{0} \\
\frac{\pi}{\alpha}\end{array}$ & 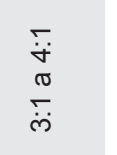 & 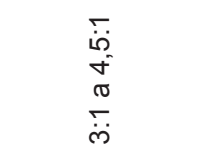 & 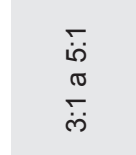 & $\begin{array}{l}\check{m} \\
\bar{\sigma} \\
\check{N}\end{array}$ \\
\hline \multicolumn{2}{|c|}{ 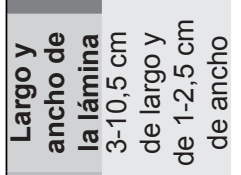 } & 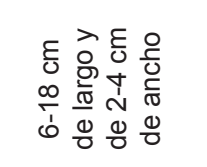 & \multicolumn{2}{|c|}{ 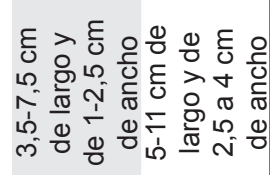 } \\
\hline 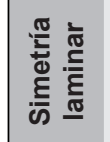 & 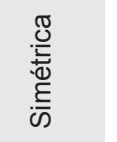 & 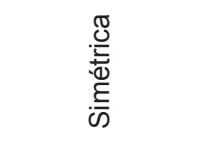 & 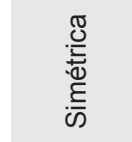 & 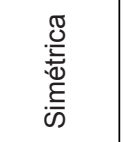 \\
\hline 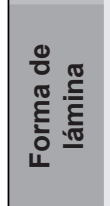 & 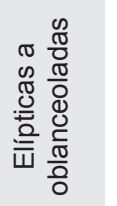 & 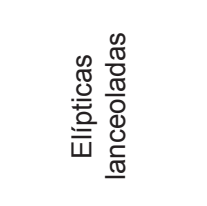 & 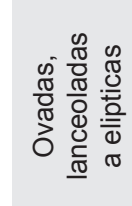 & 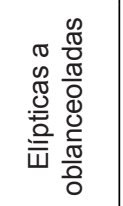 \\
\hline 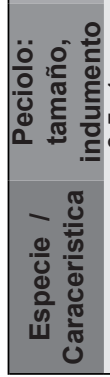 & 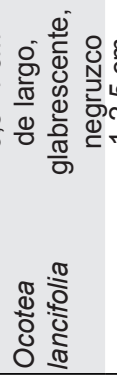 & 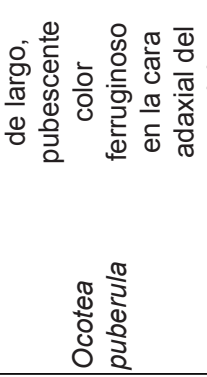 & 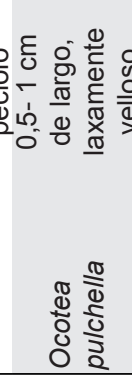 & 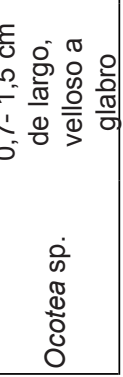 \\
\hline
\end{tabular}




\begin{tabular}{|c|c|c|c|c|c|c|c|c|c|c|c|c|}
\hline 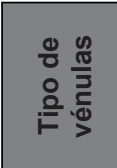 & 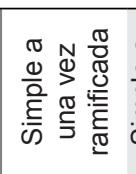 & 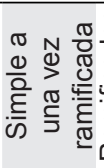 & 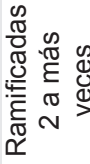 & 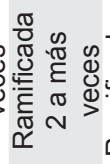 & 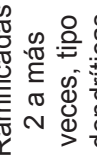 & 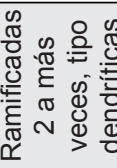 & 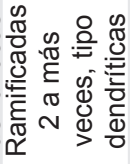 & 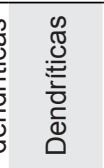 & 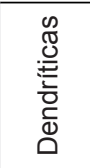 & 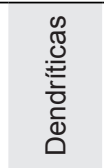 & 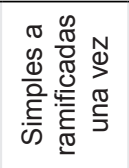 & 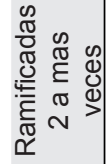 \\
\hline 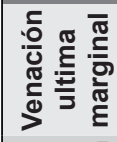 & $\begin{array}{l}\overline{\frac{\pi}{L}} \\
\frac{0}{E} \\
\frac{1}{4}\end{array}$ & 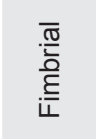 & 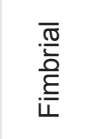 & 苍 & 管 & 恣 & 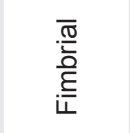 & 恣 & $\begin{array}{l}\text { O̊ } \\
\text { 这 }\end{array}$ & 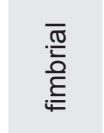 & 苍 & 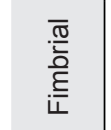 \\
\hline 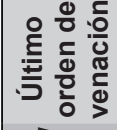 & in & in & in & is & in & in & in & is & is & is & is & in \\
\hline 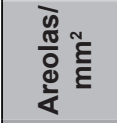 & $\stackrel{+}{\sim}$ & $\stackrel{m}{\sim}$ & $\stackrel{m}{\sim}$ & $\stackrel{m}{\sim}$ & $\stackrel{\sim}{\check{N}}$ & $\stackrel{\Upsilon}{\check{T}}$ & $\stackrel{\Upsilon}{\check{Y}}$ & $\stackrel{\Upsilon}{\Upsilon}$ & $\stackrel{\Upsilon}{\sim}$ & $\stackrel{m}{\sim}$ & $\stackrel{\Upsilon}{\stackrel{N}{ }}$ & $\stackrel{\Upsilon}{\check{Y}}$ \\
\hline $\begin{array}{l}\frac{9}{0} \\
\frac{\pi}{2} \\
\frac{d}{4}\end{array}$ & 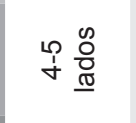 & 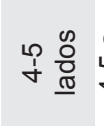 & 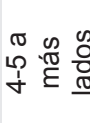 & 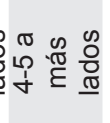 & 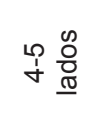 & 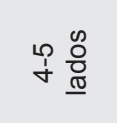 & 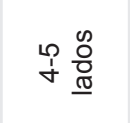 & 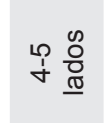 & 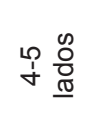 & 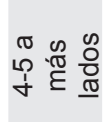 & $\sum_{\substack{j \\
\dot{\sigma}}}^{\vec{\pi}}$ & 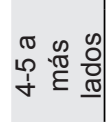 \\
\hline 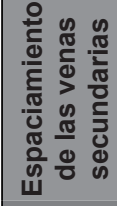 & 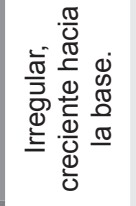 & 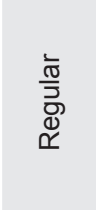 & 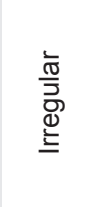 & 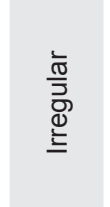 & 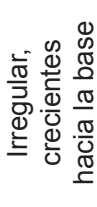 & 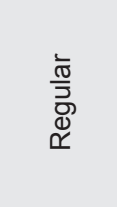 & 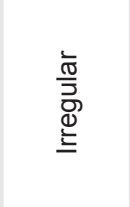 & 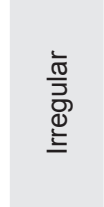 & 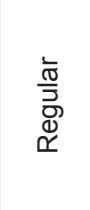 & 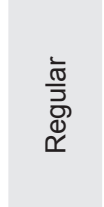 & 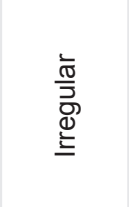 & 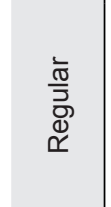 \\
\hline 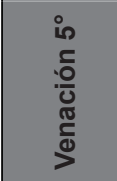 & 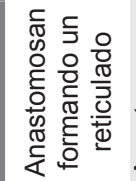 & 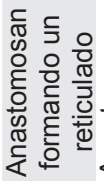 & 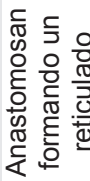 & 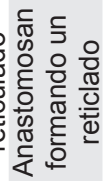 & 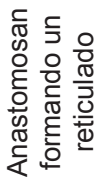 & 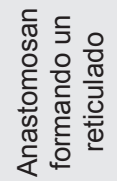 & 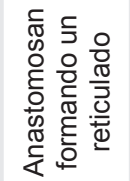 & 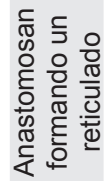 & 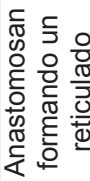 & 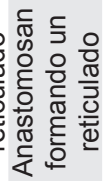 & 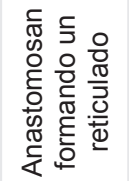 & 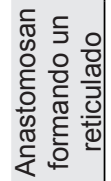 \\
\hline 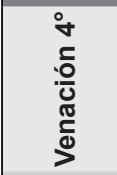 & 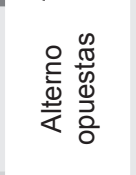 & 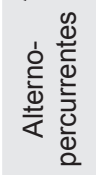 & 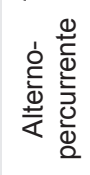 & 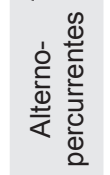 & 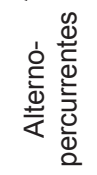 & 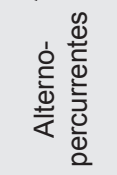 & 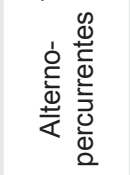 & 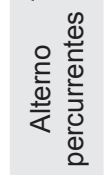 & 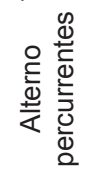 & 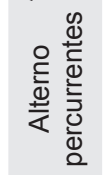 & 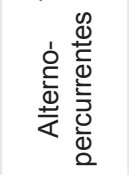 & 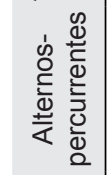 \\
\hline 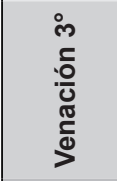 & 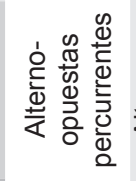 & 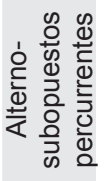 & 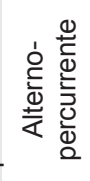 & 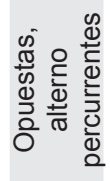 & 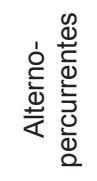 & 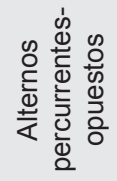 & 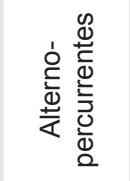 & 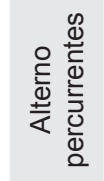 & 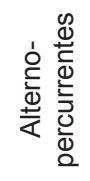 & 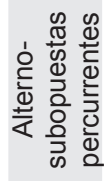 & 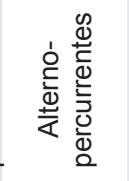 & 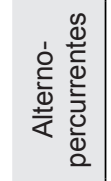 \\
\hline 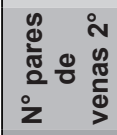 & $\stackrel{L}{q}$ & $\stackrel{\Sigma}{\Sigma}$ & $\begin{array}{l}\infty \\
i \\
i\end{array}$ & $\frac{10}{0}$ & 官 & $\stackrel{\sim}{\stackrel{N}{\infty}}$ & $\stackrel{L}{\mathfrak{q}}$ & $\begin{array}{l}\text { p) } \\
0\end{array}$ & 웃 & $\frac{0}{\infty}$ & $\begin{array}{l}\infty \\
\text { م) }\end{array}$ & $\frac{\infty}{0}$ \\
\hline 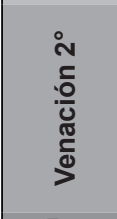 & 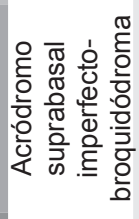 & $\begin{array}{l}\frac{\sigma}{5} \\
\overline{0} \\
\frac{0}{0} \\
\frac{0}{\bar{O}} \\
\frac{0}{0} \\
\frac{0}{0}\end{array}$ & $\begin{array}{l}\frac{\pi}{2} \\
\overline{0} \\
\frac{0}{0} \\
\frac{0}{0} \\
\frac{0}{3} \\
\frac{0}{0} \\
\frac{0}{0}\end{array}$ & 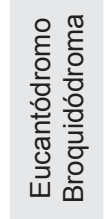 & 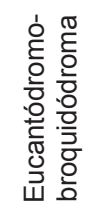 & 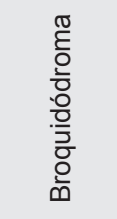 & 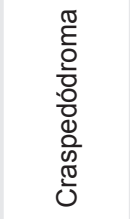 & $\begin{array}{l}\frac{\pi}{0} \\
\text { 을 } \\
\frac{0}{0} \\
\frac{0}{3} \\
\frac{0}{0} \\
\frac{0}{0}\end{array}$ & 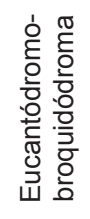 & 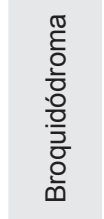 & 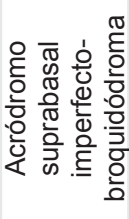 & 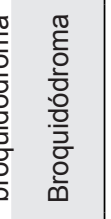 \\
\hline 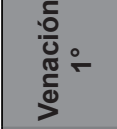 & $\begin{array}{l}\frac{\pi}{0} \\
\stackrel{0}{c} \\
\stackrel{?}{=} \\
0\end{array}$ & $\begin{array}{l}\frac{\pi}{0} \\
\frac{\pi}{2} \\
\stackrel{!}{=} \\
0\end{array}$ & 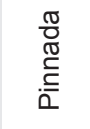 & $\begin{array}{l}\frac{\pi}{0} \\
\frac{\pi}{c} \\
\stackrel{c}{=} \\
0\end{array}$ & $\begin{array}{l}\frac{\pi}{0} \\
\stackrel{\pi}{c} \\
:= \\
0\end{array}$ & $\begin{array}{l}\frac{\pi}{0} \\
\frac{\pi}{\leftrightarrows} \\
\stackrel{0}{0}\end{array}$ & $\begin{array}{l}\frac{\pi}{0} \\
\stackrel{0}{0} \\
\stackrel{5}{=} \\
\frac{1}{0}\end{array}$ & $\begin{array}{l}\frac{\pi}{0} \\
\frac{\pi}{ \pm} \\
\stackrel{\Xi}{=} \\
0 .\end{array}$ & $\begin{array}{l}\frac{\pi}{0} \\
\frac{\pi}{c} \\
\stackrel{!}{0} \\
0 .\end{array}$ & $\begin{array}{l}\frac{\pi}{0} \\
\frac{\pi}{c} \\
\stackrel{c}{=} \\
0\end{array}$ & $\begin{array}{l}\frac{\pi}{0} \\
\frac{\pi}{c} \\
\stackrel{\underline{c}}{\alpha} \\
0\end{array}$ & $\begin{array}{l}\frac{\pi}{0} \\
\frac{\pi}{c} \\
\stackrel{!}{=} \\
0\end{array}$ \\
\hline 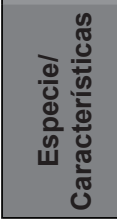 & 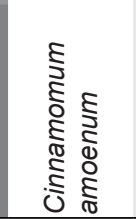 & 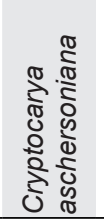 & 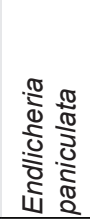 & 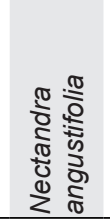 & 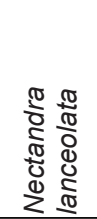 & 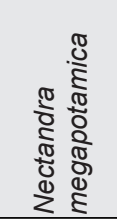 & 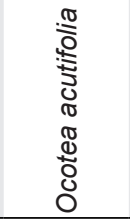 & 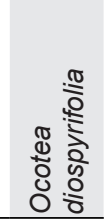 & 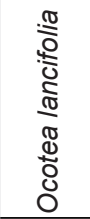 & $\begin{array}{l}\pi \\
\frac{\pi}{2} \\
0 \\
0 \\
0 \\
0 \\
\mathbb{8} \\
0 \\
0 \\
0\end{array}$ & $\begin{array}{l}\frac{\pi}{0} \\
\frac{0}{0} \\
\frac{0}{3} \\
0 \\
0 \\
0 \\
0 \\
0 \\
0\end{array}$ & $\begin{array}{l}\text { 0 } \\
\text { D } \\
8 \\
0 \\
0 \\
0\end{array}$ \\
\hline
\end{tabular}




\begin{tabular}{|c|c|c|c|c|c|c|c|c|c|c|c|c|}
\hline 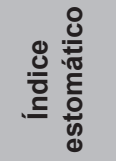 & $\begin{array}{l}\frac{0}{0} \\
\frac{0}{0} \\
\frac{0}{0}\end{array}$ & $\begin{array}{c}\frac{0}{00} \\
\frac{10}{5} \\
\frac{6}{0} \\
0\end{array}$ & $\begin{array}{l}\frac{a}{2} \\
\stackrel{5}{5} \\
\frac{5}{0}\end{array}$ & 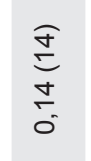 & $\frac{\widehat{o}}{\frac{0}{\grave{N}}}$ & 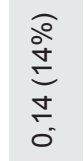 & 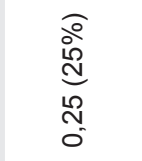 & 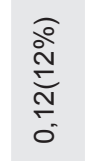 & 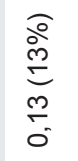 & 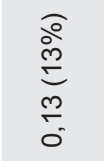 & 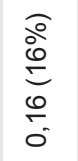 & $\begin{array}{l}\text { ঐें } \\
\text { Ñ } \\
\text { ত }\end{array}$ \\
\hline 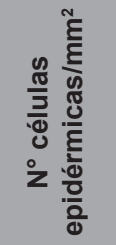 & 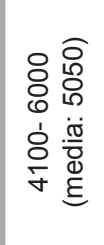 & 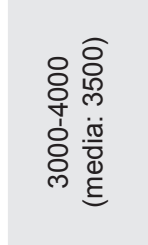 & 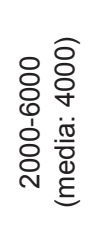 & 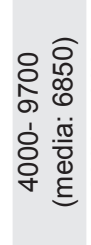 & 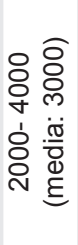 & 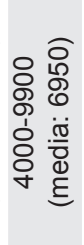 & 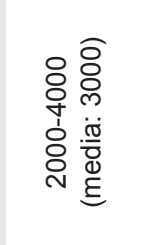 & 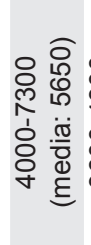 & 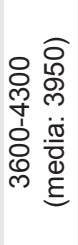 & 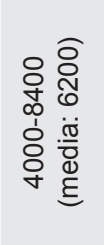 & 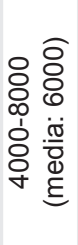 & 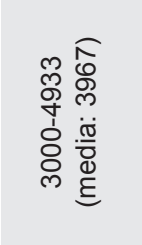 \\
\hline 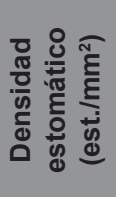 & 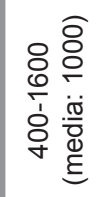 & 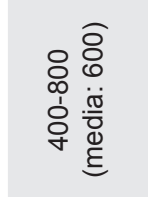 & 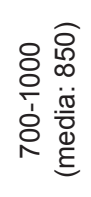 & 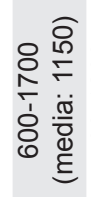 & 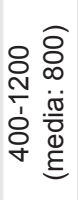 & 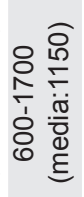 & 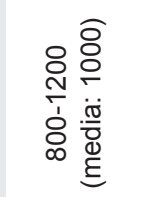 & 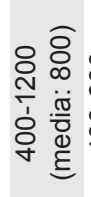 & 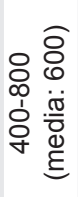 & 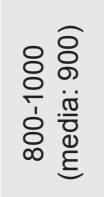 & 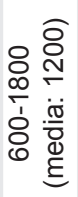 & 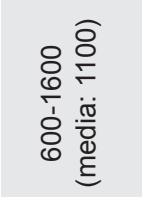 \\
\hline 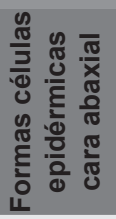 & 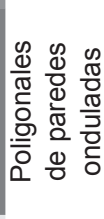 & 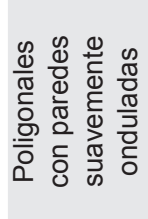 & 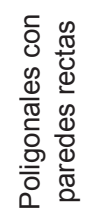 & 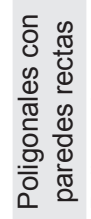 & 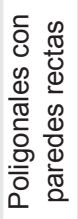 & 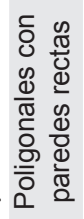 & 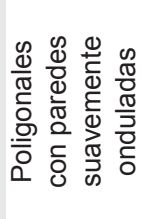 & 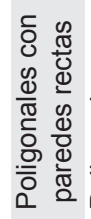 & 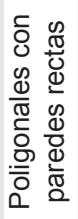 & 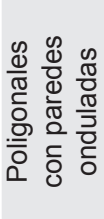 & 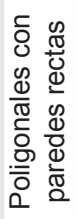 & 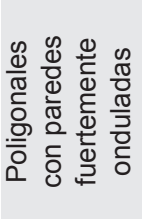 \\
\hline 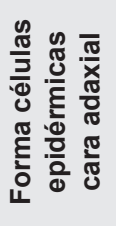 & 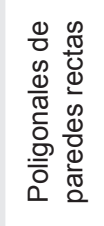 & 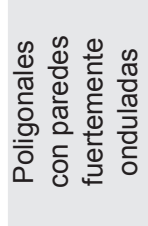 & 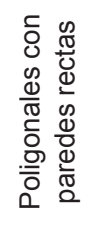 & 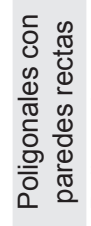 & 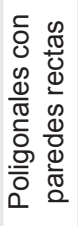 & 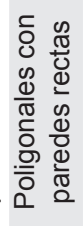 & 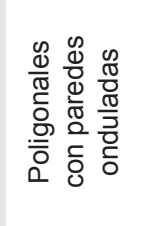 & 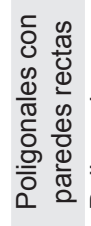 & 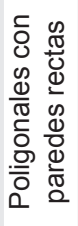 & 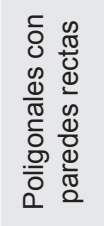 & 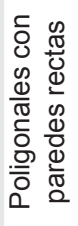 & 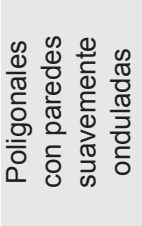 \\
\hline 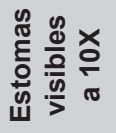 & $\begin{array}{l}\frac{\infty}{0} \\
\frac{0}{00} \\
\frac{0}{5}\end{array}$ & $\stackrel{\mathscr{0}}{\stackrel{0}{0}}$ & $\frac{0}{\frac{0}{0}}$ & $\frac{\mathscr{\Phi}}{\infty} \frac{\mathscr{\infty}}{\frac{0}{\infty}}$ & 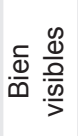 & $\frac{c}{\frac{c}{\infty}} \frac{\mathscr{e}}{\frac{0}{0}}$ & $\stackrel{\circ}{\circ} \frac{0}{0}$ & 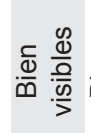 & 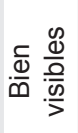 & 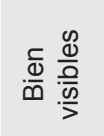 & Oे $\frac{\mathscr{0}}{0}$ & 잉 \\
\hline 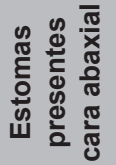 & $\bar{\omega}$ & $\bar{\omega}$ & $\bar{\omega}$ & $\bar{\omega}$ & $\bar{\omega}$ & $\bar{\omega}$ & $\bar{\omega}$ & $\bar{\omega}$ & $\bar{\omega}$ & $\bar{\omega}$ & $\bar{\omega}$ & -1 \\
\hline 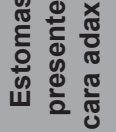 & 으 & zo & zo & 운 & z & zo & 을 & 운 & zo & zo & 은 & 2 \\
\hline 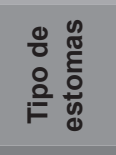 & 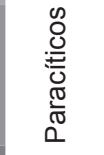 & 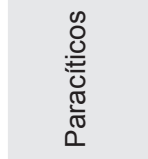 & 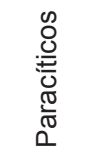 & $\begin{array}{l}0 \\
0 \\
00 \\
\overline{0} \\
0 \\
0 \\
0 \\
0 \\
0\end{array}$ & 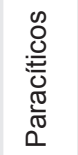 & 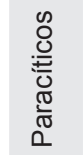 & 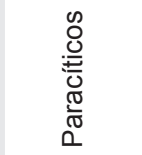 & $\begin{array}{l}00 \\
80 \\
: \frac{0}{0} \\
\frac{\pi}{\pi} \\
\overline{0} \\
0\end{array}$ & 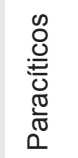 & 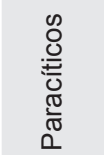 & 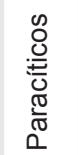 & $\begin{array}{l}0 \\
0 \\
0 \\
\frac{0}{0} \\
\frac{\pi}{\pi} \\
\frac{\pi}{0} \\
0\end{array}$ \\
\hline 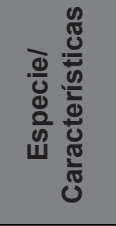 & 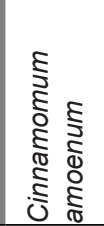 & 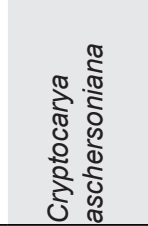 & 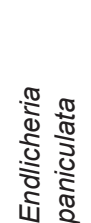 & 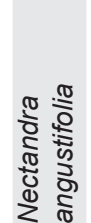 & 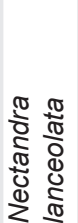 & 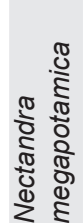 & 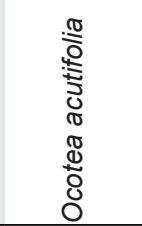 & 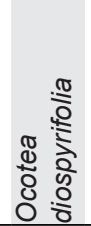 & 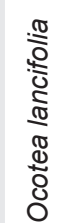 & $\begin{array}{l}\frac{\pi}{2} \\
\frac{\pi}{2} \\
0 \\
0 \\
\frac{0}{8} \\
\mathbb{8} \\
\mathbb{0} \\
0 \\
0\end{array}$ & 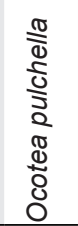 & कृ \\
\hline
\end{tabular}




\section{Discusión y Conclusiones}

De acuerdo a los resultados obtenidos puede concluirse que las especies estudiadas presentan la filotaxis alterna, hojas simples, pecioladas, sin estípulas, láminas de margen entero coincidiendo con la descripción de la familia Lauraceae realizada por Vattimo (1979).

En cuanto a las formas de las láminas foliares coincidiendo con Castiglioni (1951) fueron elípticas, lanceoladas, elíptico-lanceoladas y linearlanceoladas, esta última de valor diagnóstico para el reconocimiento de Nectandra angustifolia.

En cuanto a los peciolos las longitudes se encuentran en el rango de 0,5 a $1 \mathrm{~cm}$, para la mayoría de las especies excepto en Ocotea puberula la cual superó el centímetro alcanzando valores entre de hasta $3 \mathrm{~cm}$. La sección transversal del mismo es también un carácter útil para diferenciar especies, como entre $N$. lanceolata y Endlicheria paniculata, las cuales a pesar de su gran similitud, en el primero la sección es circular a canaliculado y en el segundo es de sección transversal asimétrica bilobulada hacia el envés del pecíolo, ésta característica también permitió diferenciar entre E. paniculata y $O$. diospyrifoli. La presencia de domacios se observó en cuatro especies, $N$. lanceolata, Cinnamomum amoenum, O. pulchella y Ocotea sp., todas en forma de escrobícula constituyendo un carácter diagnóstico a nivel de especies.

Las hojas de $N$. lanceolata, E. paniculata y $C$. amoenum presentaron un grado de pubescencia. $E$. paniculata presenta pubescencia en la nervadura principal y en las secundarias en ambas superficies de la lámina de color ferruginoso, mientras que en $N$. lanceolata solamente sobre las nervaduras en la superficie abaxial también ferruginoso; en tanto en $C$. amoenum la pubescencia es laxa y de color blanquecino en la superficie abaxial de la lámina.

El tamaño de la lámina en las muestras varió entre 3 a $18 \mathrm{~cm}$ de longitud y de 1 a $7,5 \mathrm{~cm}$ de latitud, observándose la menor longitud en $O$. acutifolia y la mayor longitud en $N$. lanceolata; asimismo las hojas más angostas se presentaron en $N$. angustifolia y las más anchas en E. paniculata, otros autores encontraron rangos por encima de los valores observados (Castiglioni, 1951; Gomes Bezerra et al., 2011).

La relación largo:ancho (L:W) de la lámina foliar se mantuvo en un rango de 2:1 a 4:1, exceptuando
$N$. angustifolia que tuvo una relación L:W de 7:1 a 12:1. Esta característica nos permite separar entre O. lancifolia (hojas elíptico-lanceoladas y L:W 3:1 a $4: 1$ ) y $N$. angustifolia (hojas linear-lanceoladas y L:W 7:1 a 12:1).

El patrón de venación primario observado en todas las especies del presente estudio es el tipo pinnado, coincidente con lo descripto por Hickey \& Wolfe (1975) y Metcalfe \& Chalk (1979) para las especies de la familia Lauraceae.

Las características exomorfológicas y el patrón de venación primario de las especies estudiadas de Nectandra ( $N$. megapotamica; N. lanceolata y $N$. angustifolia) son compatibles a las descriptas por Castiglioni (1951) y Alves \& Bagnatori Sartori (2009); en tanto que el patrón secundario, eucantódromo- broquidódromo, es coincidente al descripto por Gomes Bezerra et al. (2011), con excepción de $N$. megapotamica que presenta únicamente la broquidódromo.

El patrón de venación secundario en las especies del género Ocotea observadas fueron los tipos broquidódromos $(O$. puberula, $O$. diospyriolia y Ocotea sp.), eucamptódromo-broquidódromo ( $O$. lancifolia) acródromos suprabasal imperfectobroquidódromo $(O$. pulchella) y craspedódromo $(O$, acutifolia $)$, coincidente con los tipos descriptos por Gomes Bezerra et al. (2011) excepto para $O$. pulchella que establece un patrón .de venación secundario broquidódromo

La especie E. paniculata presentó un patrón de venación secundario broquidódromo coincidiendo con lo descripto por Gomes Bezerra et al. (2011) y Chanderbali (2004).

En Cryptocarya aschersoniana, el patrón de venación primario observado coincide con lo determinado por Moraes (2005) y el patrón de venación secundario, del tipo broquidódromo, coincide con lo descripto por Gomes Bezerra et al. (2011).

En C. amoenum el patrón observado ya fue descripto por Lorea-Hernandez (1996), y el patrón secundario acródromo suprabasal imperfecto broquidódromo observado coincide con lo descripto Baruah \& Nath (2006) por para otras especies del mismo género.

El número de pares de nervaduras secundarias observadas fue de 4 a 18 pares. Las especies de $N$. lanceolata, C. amoenum, O. acutifolia, O. diospyrifolia, O. pulchella y E. paniculata 
presentaron un rango de 4-7, mientras que las otras especies presentaron entre 8 a 18 pares de venas secundarias.

El distanciamiento entre las venas secundarias se clasifican en las categorías de regulares o irregulares, y constituye un carácter de diagnóstico dado que el $50 \%$ de las especies presentan un distanciamiento regular ( $N$. megapotamica; Cryptocarya aschersoniana, O. lancifolia, O. puberula y Ocotea sp.), las restantes con distanciamiento irregular.

Todas las especies descriptas presentan las nervaduras de tercer y cuarto orden alternopercurrentes y las nervaduras del $4^{\circ}$ y $5^{\circ}$ orden son las que definieron las areolas poligonales bien desarrolladas con $4-5$ a más lados, por lo cual estas características no se consideran relevantes para la diferenciación de especies.

El número de areolas $/ \mathrm{mm}^{2}$ determinado en las especies es de 1 a 4 . Las especies Cryptocarya aschersoniana, C. amoenum, O. puberula y $E$. paniculata presentaron 2-4 areolas $/ \mathrm{mm}^{2}$ en restantes especies presentaron de 1-2 areolas $/ \mathrm{mm}^{2}$.

La mayoría de las especies presentaron vénulas ramificadas más de dos veces (dendríticas); vénulas simples o ramificadas una sola vez se presentaron en Cryptocarya aschersoniana, Cinnamomum. amoenum y en $O$. pulchella, siendo un carácter interesante para poder separar a las especies como en Cryptocarya aschersoniana (simples y una vez ramificada) y $N$. megapotamica (ramificadas 2 o más veces).

El $50 \%$ de las especies presentó la última vena marginal del tipo fimbrial y el $50 \%$ restante el tipo en arcos.

Todas las especies del presente estudio son hipostomáticas, con estomas del tipo paracítico. La densidad estomática presenta un rango de 400-1800 estomas $/ \mathrm{mm}^{2}$, coincidente con el rango determinado por Larcher (2003) y por Napp (1974) citado en Cañizares et al. (2003), Baruah \& Nath (2006) encontraron 802 estomas $/ \mathrm{mm}^{2}$ en la cara abaxial en Cinnamomum pauciflorum lo cual coincide con el rango encontrado en este trabajo para $C$. amoenum; siendo la alta intensidad de luz y bajos niveles de $\mathrm{CO}_{2}$ factores que durante el desarrollo de la hoja tienden a aumentar o disminuir la densidad de los estomas (Campbell \& Reece, 2007), además las condiciones ambientales y nutricionales influyen sobre los valores de densidad estomática e índice estomático (Esau, 1972; Wilkinson, 1979; Roth et al., 1986, citados en Cañizares et al., 2003).

Las paredes de las células epidérmicas fundamentales presentaron en algunos casos diferencias entre la cara adaxial y abaxial, como en $C$. amoenum y $O$. puberula que presentaron en la cara adaxial células epidérmicas poligonales con paredes rectas y en la cara abaxial células poligonales con paredes onduladas; Ocotea sp., en cambio, presentó en la cara adaxial células con paredes suavemente onduladas y en la cara abaxial células con paredes fuertemente onduladas; Cryptocarya aschersoniana presentó en la cara adaxial células con paredes fuertemente onduladas y en la cara abaxial células con paredes suavemente onduladas; las demás especies presentaron en ambas caras células epidérmicas poligonales con paredes rectas.

Las características de la epidermis foliar observadas en $N$. megapotamica, $N$. lanceolata, O. puberula y O. pulchella son coincidentes con lo descripto por Ceolin et al. (2009). Esta característica, puede ser un carácter sumamente importante para poder separar en grupos las especies en estudios más detallados para la identificación de las mismas, en el caso en que los caracteres macroscópicos no permitan separar las especies.

No se observaron un único carácter que sea constante en las especies de un mismo género y que permitan distinguirlas o separarla de los otros géneros, por lo cual para la elaboración de la clave se utilizó una combinación de los mismos para el reconocimiento de las especies de la familia Lauraceae presentes en Misiones.

\section{Agradecimientos}

A la Facultad de Ciencias Forestales de la Universidad Nacional de Misiones por brindar el espacio y los materiales de laboratorio para poder realizar este trabajo.

\section{Bibliografía}

ASH, A., B. ELLIS, L. HICKEY, K. JOHNSON \& S. WING. 1999. Manual of Leaf Architecturemorphological description and categorization of dicotyledonous and net-veined monocotyledonous 
angiosperms by Leaf Architecture Working Group. Smithsonian Institute, Washingtong D.C., USA.

ALVES, F. M. \& A. L. BAGNATORI SARTORI. 2009. Nectandra Rol. ex Rottb. (Lauraceae) no Mato Grosso do Sul, Brasil. Acta Bot. Bras. 23: 118-129.

BAITELLO, J. B. 2001. Novas espécies de Lauraceae para a Flora Brasileira. Acta Bot. Bras. 15: 445-450.

BARUAH, A. \& S. NATH. 2006. Leaf anatomy and essential oil characters of Cinnamomum pauciflorum Nees. - a potential spice crop from North- east India. Journal of Spices and Aromatic Crops 15: 52-56.

BROTTO, M. L., E. PEREIRA DOS SANTOS \& J. B. BAITELLO. 2009. Lauraceae no Morro dos Perdidos (Floresta Atlântica), Paraná, Brasil. Rodriguésia 60: 445- 459.

CABRERA, A. L. 1994. Regiones Fitogeográficas Argentina. Enciclopedia Argentina de Agricultura y Jardinería. Fascículo 1, Tomo II, pp. 85. Editorial ACME S.A.C.I. Buenos Aires.

CAMPBELL, N. A \& J. B. REECE. 2007. Biología, $7^{\circ}$ ed. Médica Panamericana, Buenos Aires, Madrid.

CAÑIZARES, A; M. E. SANABRIA; D.A. RODRIGUEZ \& Y. PEROZO. 2003. Características de los estomas, índice y densidade estomática de las hojas de Tahití (Citrus latifolia Tanaka) injertada sobre ocho patrones cítricos. Revista UDO Agrícola 3: 59-64.

CARDOSO, C.M.V. \& M.G. SAJO. 2006. Nervação foliar em espécies brasileiras de Myrtaceae Adans. Acta Bot. Bras. 20: 657- 669.

CASTIGLIONI, J. A. 1951. Lauráceas argentinas: Género Nectandra. Bol. Soc. Argent. Bot. 4: 66 - 94.

CEOLIN, G. B.; J. M. ROSITO \& T. S. CANTODOROW. 2009. Leaf Surace Characters Applied to Lauraceae Taxonomy in a Seasonal Forest Brazil. Braz. Arch. Biol. Technol. 52: 1453-1460.

CHANDERBALI, A. S. 2004. Endlicheria (Lauraceae). Flora Neotropica, Vol. 91: 1-141.

CHANDERBALI, A. S., H. Van der WERFF \& S. S. RENNER. 2001. Phylogeny and historical biogeography of Lauraceae: evidence from the chloroplast and nuclear genomes. Ann. Missouri Bot. Gard. 88: 104-134.

DIZEO DE STRITTMATTER, C. G. 1973. Nueva Técnica de Diafanización. Bol. Soc. Argent. Bot. 15: $126-129$.

GOMES BEZERRA, K. M., L. H. SOARES-SILVA \& S. M. GOMES. 2011. Arquitectura foliar de las Lauraceae del Distrito Federal, Brasil, y nuevos patrones de venación propuestos. Gayana Bot. 68: $1-15$.

GONZÁLES, C. 2011a. Arquitectura foliar de las espécies de Myrtaceae nativas de la Argentina I: Grupo "Myrcia", Myrceugenia" y "Plinia". Bol. Soc. Argent. Bot. 46: 41-63.

GONZÁLES, C. 2011b. Arquitectura foliar de las espécies de Myrtaceae nativas de la Argentina II: Grupo "Myrteola"y "Pimienta". Bol. Soc. Argent. Bot. 46: 65-84.

GONZÁLES, C. 2011c. Arquitectura foliar de las espécies de Myrtaceae nativas de la Argentina III: Grupo "Eugenia". Bol. Soc. Argent. Bot. 46: 85-104.

GUANTAY, M. E. 2004a. Morfoanatomía y arquitectura foliar de Myrrhinium atropurpureum var. octandrum Benth. (Myrtaceae). Lilloa 41: 31-39. Argentina.

GUANTAY, M. E. 2004b. Morfoanatomía y arquitectura foliar de Blepharocalyx salicifolius (Kunth) O. Berg. (Myrtaceae). Lilloa 41: 85-92. Argentina.

GUANTAY, M.E. 2008. Anatomía y arquitectura foliar de Amomyrtella güili (Speg.) Kausel (Myrtaceae). Lilloa 45: 66- 72. Argentina.

HICKEY, L.J. 1974. Clasificación de la arquitectura de las hojas de dicotiledóneas. Bol. Soc. Argent. Bot. 16: 1-33.

HICKEY, L. J. 1979. A revised classification of the architecture of dicotyledonous leave. In: METCALFE, C. \& L. CHALK (eds.), Anatomy of the dicotyledons, pp. 1:25-39.: Clarendon Press, Oxford.

HICKEY, L. J. \& J. A. WOLFE. 1975. The bases of angiosperm phylogeny: vegetative morphology. Ann. Missouri Bot. Gard. 62: 538- 589.

INOUE, M. T.; C. V. RODERJAN \& Y. S. KUNIYOSHI. 1984. Projeto madeira do Paraná. Fundação de Pesquisas Florestais, Curitiba, Brasil.

KLEIN, R. M.; A. REIS \& R. REITZ. 1979. Madeiras do Brasil. Ed. Lunardelli, Florianopolis, Brasil.

KÖPPEN, W. 1948. Climatología. Fondo de Cultura Económica, México.

LARCHER, W. 2003. Ecophysiology and stress physiology of functional groups. Physiological plant ecology 4th ed. Springer, Berlin.

LOREA-HERNANDEZ, F. G. 1996. A Systematic Revision of the Neotropical Species of Cinnamomum Schaeffer (Lauraceae). University of Missouri- ST. Louis.

LUO, Y. \& Z. K. ZHOU. 2002. Leaf architecture in Quercus subgenus Cyclobalanopsis. (Fagaceae) from China. Bot. J. Linn. Soc. 140: 283-295.

MANTESE, A. \& D. MEDAN. 1992. Anatomía y arquitectura foliares de Retamilla (Rhamnaceae). Darwiniana 31: 253-259.

MALLA, L.; L. GALLEGO; S. VILLAMIL \& M. B. MUJICA. 1998. Arquitectura foliar de tres géneros monotípicos Sudamericanos de Fabaceae. Darwiniana 35: 1 - 8. Argentina.

MARQUES, C. A. 2001. Importância econômica da família Lauraceae Lindl. Floresta e Ambiente 8:195 $-206$.

MARTÍNEZ CABRERA, D.; T. TERRAZAS \& F. ZAVALA CHAVEZ. 2003. Arquitectura foliar 


\section{P. A. Poszkus Borrero et al. - Arquitectura foliar de Lauraceae de Misiones}

y anatomía de Quercus sartorii y Q. xalapensis (Fagaceae). Bol. Soc. Bot. Mex. 73: 63-72.

MARTÍNEZ MELLÁN, M. \& S. R. S. CEVALLOS FERRIZ. 2005. Arquitectura foliar de Anacardiaceae. Revista Mexicana de Biodiversidad 76: 137-190.

METCALFE, C. R. \& L. CHALK. 1979. Anatomy of the Dicotyledons. Vol. 1: Systematic anatomy of leaf and stem, with a brief history of the subject. $2^{\text {nd }}$ ed. Clarendon Press, Oxford.

MORAES, P. L. R. DE. 2005. Sinopse das Lauráceas nos Estados de Goiás e Tocantins, Brasil. Biota Neotropica 5: 253-270.

PALAVECINO, J. \& C. MAIOCCO. 1995. Levantamiento del médio físico del área de investigación forestal Guaraní. Revista Yvyraretá 6: 50-62.

PRABHAKAR, M. 2004. Structure, delimitation, nomenclature and classification of dtomata. Acta Botánica Sinica 46: 242-252.

ROMERO, E. \& M. DIBBERN. 1982. Arquitectura foliar de las especies de Myrtaceae de la Provincia de Buenos Aires. Bol. Soc. Argent. Bot. 20: 255 - 266.

ROHWER, J. G. 1993. Lauraceae. In: Kubitzki, K., J. G. Rohwer \& V. Bittrich (eds.), The families and genera of vascular plants. Flowering plants. Dicotyledons, pp. 2: 336-391. Springer-Verlag, Berlin.

RUIZ, A. I, M. I. MERCADO, M. E. GUANTAY \& G. I. PONESSA. 2009. Morfoanatomía y arquitectura foliar de Schinus areira (Anacardiaceae). Lilloa 46: 137-146.

RUZIN, S. E. 1999. Plant Microtechnique and Microscopy. $2^{\text {nd }}$ ed. Oxford University Press, New York.
SACK, L., C. SCOFFONI, A. D. Mc KOWN, K. FROLE, M. RAWLS, C. HAVRAN, H. TRAN \& T. TRAN. 2012. Developmentally based scaling of leaf venation architecture explains global ecological patterns. Nature Communications 3:837.

VAN DER WERFF, H. \& H. G. RICHTER, 1996. Toward an improved classification of Lauraceae. Ann. Missouri Bot. Gard. 83: 409-418.

VATTIMO, I. DE. 1979. Lauráceas. I Parte. 1. Cryptocarya, 2. Endlicheria, 3. Licaria, 4. Aiouea, 5. Aniba. Flora ilustrada Catarinense. pp. 1-50. Herbario Barbosa Rodriguez, Itajai, Santa Catarina, Brasil.

WILKINSON, H. P. 1980. The plant surface (mainly leaf). In: Metcalfe, CR \& L. Chalk (eds.), Anatomy of the Dicotyledons, pp. 97-165. Claredon Press, Oxford.

ZULOAGA, F. O., O. MORRONE \& M. BELGRANO. 2009. Catálogo de plantas vasculares del Cono Sur. Argentina, sur de Brasil, Chile, Paraguay y Uruguay. Missouri Botanical Garden Press. http:// www2.darwin.edu.ar/Proyectos/FloraArgentina/ FA.asp.

Recibido el 6 de mayo de 2015, aceptado el 18 de diciembre de 2015. 
